\title{
Facile syntheses of building blocks for the construction of phosphotyrosine mimetics
}

\author{
G. Stuart Cockerill, ${ }^{a}$ Howard J. Easterfield, ${ }^{b}$ Jonathan M. Percy ${ }^{b}$ and Stéphane Pintat ${ }^{b}$ \\ ${ }^{a}$ GlaxoWellcome Medicines Research Centre, Gunnels Wood Road, Stevenage, Herts, \\ UK SG1 $2 N Y$ \\ ${ }^{b}$ School of Chemistry, University of Birmingham, Edgbaston, Birmingham, UK B15 2TT
}

Received (in Cambridge, UK) 25th May 2000, Accepted 15th June 2000

Published on the Web 26th July 2000

\begin{abstract}
The copper-catalysed zinc phosphonate chemistry described by Yokomatsu and Shibuya can be used to enter the classical organometallic coupling repertoire via Stille and Suzuki-Miyaura couplings. 1,4-Diiodobenzene underwent coupling with the organozinc reagent derived from diethyl bromodifluoromethylphosphonate with copper(I) catalysis to afford diethyl (4-iodophenyl)difluoromethylphosphonate. Higher yielding couplings were run with (4-trifluoromethylsulfonyloxy)- and (4-nonafluorobutylsulfonyloxy)-iodobenzenes. The iodide and the triflate coupled under palladium-catalysed conditions with a range of stannanes and boronic acids in moderate to excellent yields. Shibuya-Yokomatsu couplings were also successful with more functionalised iodoarenes and heteroarenes presenting the important phosphate mimic on a range of scaffolds.
\end{abstract}

Non-hydrolysable phosphotyrosine mimics including (difluorophosphonomethyl)phenylalanine $\mathbf{1}$ have aroused the interest<smiles>N[C@@H](Cc1ccc(C(F)(F)P(=O)(O)O)cc1)C(=O)O</smiles>

of many groups concerned with the role of transient protein phosphorylation in disease (notably cancer) and the possible importance of the process as a target for the development of new therapeutic agents and strategies. ${ }^{1,2}$ The current literature burgeons as (particularly industrial) groups define the selectivity of binding events and bases for molecular recognition of inter alia Grb-2, ${ }^{3-5}$ Lck SH-2, ${ }^{6,7} \mathrm{Src}-\mathrm{SH} 2,{ }^{8-12}$ and $\mathrm{p}-85 \mathrm{C}-\mathrm{SH} 2{ }^{13}$ receptor sites. The fruitful collaboration between Burke and Barford has yielded profound insight into small molecule ligand-large molecule receptor interactions based upon a number of key crystal structures, ${ }^{14}$ providing a solid basis for molecular design of ligands. ${ }^{15}$ Mimesis responds to a number of imperatives; as the binding site recognises a tetrahedral phosphate monoester dianion within a hydrogen bonding array to two arginine residues, charge and shape are critical. Difluorophosphonates confer hydrolytic stability while preserving the correct charge and geometry. Other mimetics were described recently by Fretz $\left(\mathrm{ArOCF}_{2} \mathrm{CO}_{2} \mathrm{H}\right)^{16}$ and Burke et al. $\left(\mathrm{ArCF}_{2}-\right.$ $\mathrm{COOH}){ }^{17}$ they share the advantage of lower charge (an asset for potential in vivo applications) but offer different geometries to the recognition array. These mimetics are also straightforward to synthesise, ${ }^{18-20}$ carbene chemistry is effective in the former case, while the recent coupling approach to the latter described by Kumadaki ${ }^{21}$ and co-workers represents a significant advance. Malonates (OMt and FOMt) also have a role to play and have been effective probes and inhibitors in certain cases. $^{22,23}$

Modern methods for the generation of molecular diversity have not to our knowledge been deployed extensively in this area of chemistry - the attempts by Ganesan ${ }^{24}$ and Bergnes ${ }^{25}$ to synthesise libraries of phosphate mimetics as potential phosphatase inhibitors provide rare examples and illustrate the need for readily-available functionalised scaffolds bearing phosphate mimetics. Following our recent communication in this area, ${ }^{26}$ we wish to describe the scope, generality and limitations of palladium-catalysed coupling reactions investigated in our laboratory.

As described by Shibuya, ${ }^{27,28}$ 1,4-diiodobenzene underwent smooth coupling (Scheme 1) to afford the iodophenyl phos-

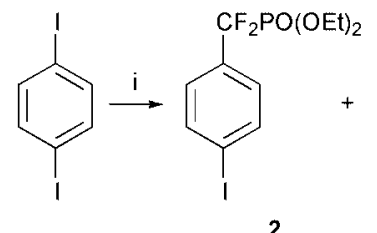

2<smiles>CCO[O+]=C(OCC)c1ccc(C(=O)OCC)cc1</smiles>

3
$\mathrm{CF}_{2} \mathrm{PO}(\mathrm{OEt})_{2}$
$\mathrm{CF}_{2} \mathrm{PO}(\mathrm{OEt})_{2}$

4
Scheme 1 Reagents and conditions: $\mathrm{i}, \mathrm{BrZnCF}_{2} \mathrm{PO}(\mathrm{OEt})_{2}, \mathrm{CuBr}$, DMA, rt, sonicate 3 hours then 24 hours at rt.

phonate $\mathbf{2}$ and bis-coupled $\mathbf{3}$ which could be separated from each other, and from homo-coupled $\mathbf{4}$, by simple column chromatography. Intermediates such as $\mathbf{2}$ also present an opportunity for the generation of molecular diversity through exploitation of the second carbon-iodine bond in a palladiumcatalysed coupling reaction. Of course, aryl triflates are also accepted in this repertoire of reactions, whereas the Shibuya coupling does not run for aryl triflate substrates thus avoiding the formation of bis-coupled $\mathbf{3}$, so we decided to explore the behaviour of (iodoaryl)perfluoroalkanesulfonates under the Shibuya conditions.

Consistent with the reactivity described by Shibuya, iodotriflate 5a, prepared from 4-iodophenol on a $50 \mathrm{~g}$ scale under standard conditions (triflic anhydride, pyridine, $\left.0{ }^{\circ} \mathrm{C}, 95 \%\right)^{29}$ underwent efficient coupling under sonication conditions to afford $6 \mathbf{a}$ in a pleasing $66 \%$ isolated, purified yield (Scheme 2). Typically, 2 equivalents of the copper-zinc reagent were used for these couplings. Intermediate $\mathbf{6 a}$ could be stored for extended periods in the freezer without decomposition. The nonaflate (nonafluorobutanesulfonate) $\mathbf{5 b}$ was prepared following a literature procedure ${ }^{30}$ and coupled in a similar way affording $\mathbf{6 b}$ in $75 \%$ yield. Short periods of sonication were required in both cases. The more bulky diisopropyl phosphonate 7 could be 
Table 1 Shibuya-Yokomatsu couplings on electron-rich, functionalised benzenoid and heteroaromatic templates

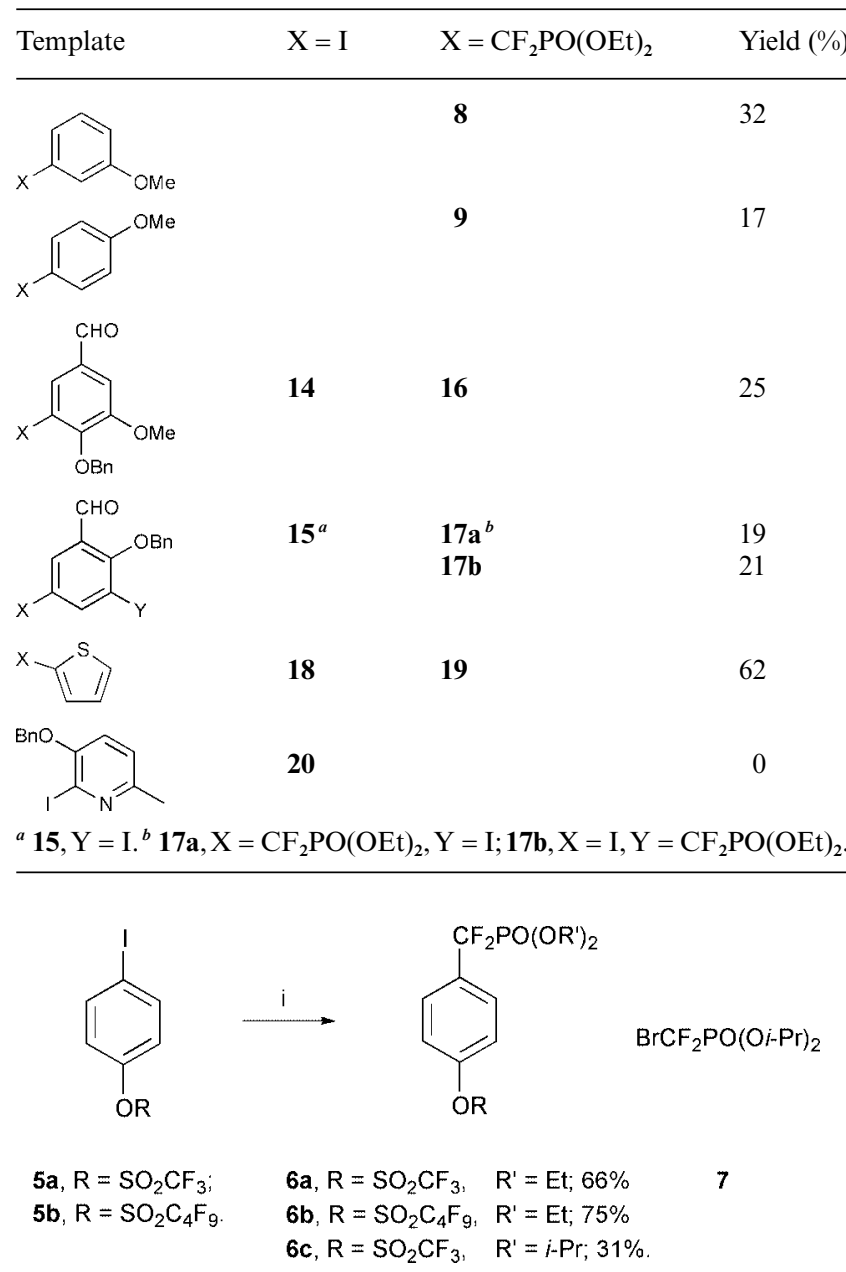

Scheme 2 Reagents and conditions: i, $\mathrm{BrZnCF}{ }_{2} \mathrm{PO}\left(\mathrm{OR}^{\prime}\right)_{2}, \mathrm{CuBr}$, DMA, rt, sonicate 3 hours then 24 hours at rt.

coupled via the corresponding organozinc reagent with iodotriflate under similar conditions to afford $\mathbf{6 c}$ though in rather lower $(31 \%)$ yield. Table 1 summarises additional results with a range of aromatic templates. Contrasting results were obtained when $m$ - and $p$-iodoanisole were exposed to 1.5 equivalents of the coupling reagent; educts $\mathbf{8}$ and $\mathbf{9}$ were obtained in 32 and $17 \%$ yields respectively suggesting that the rate-determining step in the coupling sequence is oxidative addition of an organometallic reagent into the $\mathrm{C}-\mathrm{I}$ bond. ${ }^{31}$ Similar behaviour was observed in the efficient coupling of activated substrate $\mathbf{1 2}$ (67\%) derived from commercial 10 (Scheme 3). Substrates 14<smiles></smiles>

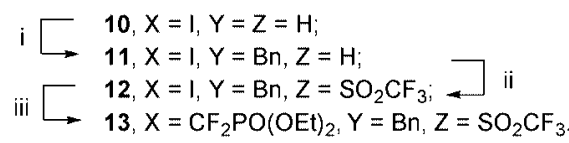

Scheme 3 Reagents and conditions: i, $\mathrm{BnBr}, \mathrm{KF}, \mathrm{DMF}, \mathrm{rt}$; ii, $\mathrm{Tf}_{2} \mathrm{O}$, pyridine, $0{ }^{\circ} \mathrm{C}$; iii, $\mathrm{BrZnCF}_{2} \mathrm{PO}(\mathrm{OEt})_{2}, \mathrm{CuBr}$, DMA, rt, sonicate 3 hours then 24 hours at rt.

and 15 coupled rather sluggishly to afford $\mathbf{1 6}(25 \%)$, and $\mathbf{1 7 a}$ $(19 \%)$ and $\mathbf{1 7 b}(21 \%)$ respectively. In $\mathbf{1 5}$, the two C-I bonds appear rather similar electronically and the two insertions occur at almost identical rates despite a difference in steric hindrance. However, in the original report of the coupling reaction by
Table 2 Stille couplings of $6 \mathbf{a}^{a}$

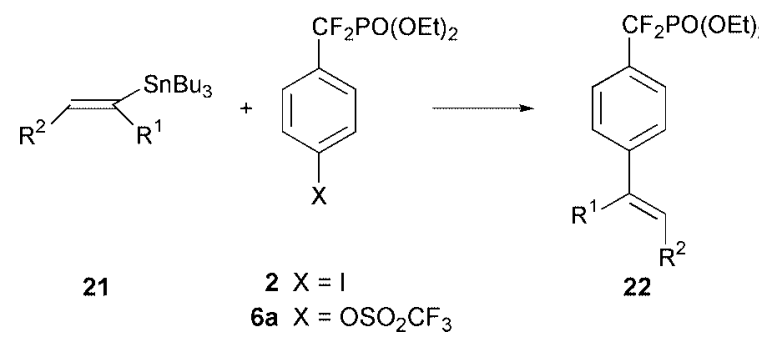

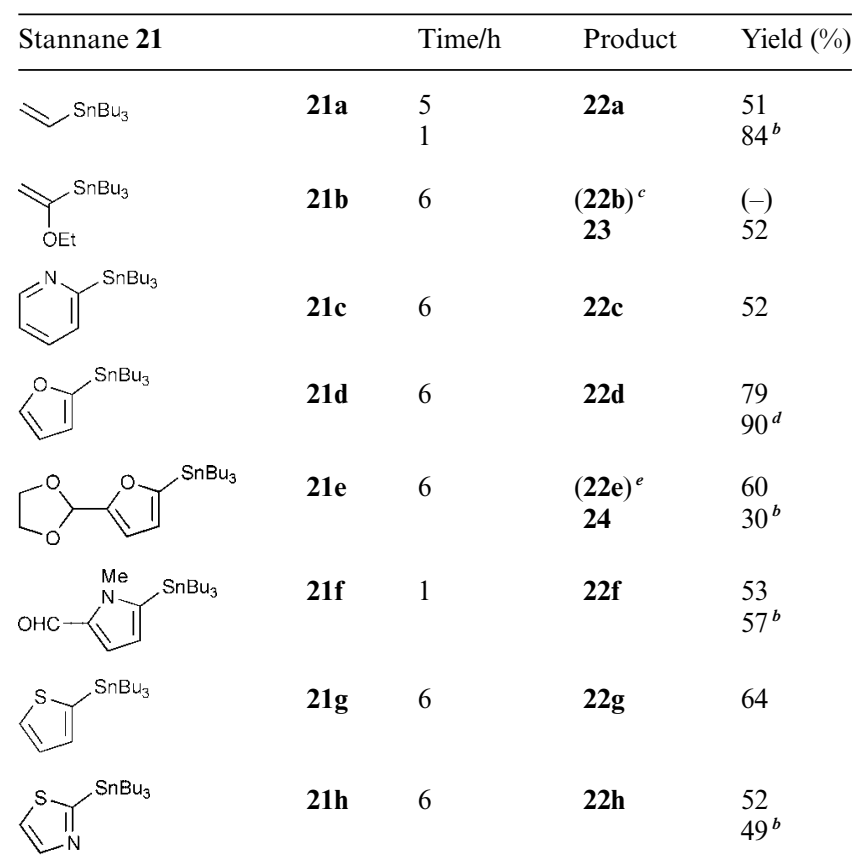

${ }^{a} 1.0$ equiv. 6a, 1.0 equiv. stannane, $5 \% \mathrm{Pd}\left(\mathrm{PPh}_{3}\right)_{2} \mathrm{Cl}_{2}, \mathrm{DMF}, 60{ }^{\circ} \mathrm{C} .{ }^{b}$ Yield from 2 under these conditions. ${ }^{c}$ The methyl ketone 23 was isolated after hydrolysis. ${ }^{d} 5 \% \mathrm{Pd}_{2} \mathrm{dba}_{3} \cdot \mathrm{CHCl}_{3}, 10 \% \mathrm{CuI}, 20 \% \mathrm{PPh}_{3}, \mathrm{DMF}, 60{ }^{\circ} \mathrm{C}$. ${ }^{e}$ The aldehyde $\mathbf{2 4}$ was isolated after hydrolysis.

Yokomatsu and co-workers, ${ }^{28}$ methyl 2-iodo- and 4-iodobenzoate coupled in identical $(99 \%)$ yields suggesting that the steric hindrance provided, at least, by an $\mathrm{sp}^{2}$ hybridised array, is minimal. Commercial heteroaryl 2-iodothiophene $\mathbf{1 8}$ displayed the expected high reactivity and underwent Shibuya-Yokomatsu coupling to 19 in $62 \%$ yield. Coupling failed completely with 20 in which a benzyloxy group flanks the coupling site and in which a pyridyl nitrogen is also present. From these results, we conclude that protection of phenolic hydroxy groups may be best undertaken using electron withdrawing sulfonate esters rather than ethers. ${ }^{32}$

Stille coupling reactions of $\mathbf{2}$ and $\mathbf{6 a}$ with a range of aliphatic, aryl and heteroaryl tributylstannanes $\mathbf{2 1 a}-\mathbf{h}$ afforded coupling products $\mathbf{2 2} \mathbf{a}-\mathbf{h}$ in moderate to high yields, thus presenting the phosphate mimicking group on a wide range of biaryl scaffolds (Table 2), in clear contrast to the results reported by the Tokyo group who found the triflate an inefficient precursor for coupled products. Coupling conditions were not optimised exhaustively but our best results were achieved in hot $\left(60^{\circ} \mathrm{C}\right) \mathrm{DMF}$ with either $\mathrm{Pd}\left(\mathrm{PPh}_{3}\right)_{2} \mathrm{Cl}_{2}(5 \mathrm{~mol} \%)$ or $\mathrm{Pd}_{2} \mathrm{dba}_{3} \cdot \mathrm{CHCl}_{3}$ complex $(2.5 \mathrm{~mol} \%)$; tetrakis(triphenylphosphino)palladium(0) and (dppb) $\mathrm{PdCl}_{2}$ were ineffective catalysts for the reaction in our hands. The addition of lithium chloride to the Stille reactions either inhibited the coupling, or resulted in decomposition of $\mathbf{2}$ or $\mathbf{6 a}$. Lower yields were obtained when couplings were attempted in 1,4-dioxane either at room temperature or at reflux, but Stille couplings with 2 proceeded in moderate yield in THF, suggesting that oxidative addition is indeed the slow step in the sequence and that nucleophilic attack at phosphorus (or elsewhere) competes when this 
initial step becomes laboured. Triflate $\mathbf{6 a}$ performed as well as, if not better than iodide $\mathbf{2}$ in most cases. Bulkier alkoxy groups at phosphorus have been used traditionally to solve the problem of nucleophilic attack but we did not explore this possibility in view of the success of most of the couplings. Increases in yield (up to $90 \%$ for 21d) were obtained under one set of FarinaLiebeskind conditions ${ }^{33}$ in which copper(I) iodide (10 mol\%) and $\mathrm{Ph}_{3} \mathrm{P}(20 \mathrm{~mol} \%)$ were added. We were also able to use $\mathbf{1 3}$ efficiently in Stille coupling with (tributylstannyl)furan; product 25 was afforded under the $\mathrm{CuI}-\mathrm{Ph}_{3} \mathrm{P}$ conditions in good<smiles>CCOCc1ccc(C(C)=O)cc1</smiles>

23<smiles>CCOC(=O)Cc1ccc(-c2ccco2)c(C(=O)OCc2ccccc2)c1</smiles>

25

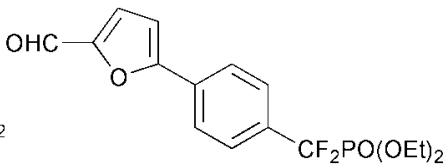

24

26

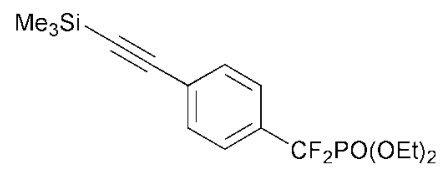

$(70 \%)$ yield. Direct coupling with (trimethylsilyl)ethyne also proceeded well to afford $\mathbf{2 6}(80 \%$ yield) under the palladiumcatalysed conditions described by Chen and Yang. ${ }^{34}$

Suzuki coupling conditions were based on the findings of Shieh and Carlson. ${ }^{35}$ For the reaction between 6a and 2,3dimethoxyphenylboronic acid, the heterogeneous conditions $\left(\mathrm{Pd}\left(\mathrm{PPh}_{3}\right)_{4}, \mathrm{~K}_{2} \mathrm{CO}_{3}, \mathrm{PhMe}, 90{ }^{\circ} \mathrm{C}\right)$ afforded none of the desired biaryl but the homogeneous conditions which use the same catalyst and triethylamine base in DMF were more successful and the biaryl was formed. Table 3 shows the scope of the chemistry. The acceptable yield of the 4-bromo biaryl 27c is of note, as is the successful coupling with the alkylboronic acid in the absence of any activating additive (to form the ate-complex).

These results show tolerance by the difluoromethylphosphoryl group of non-nucleophilic coupling conditions, and the availability of aryl phosphonate building blocks of different levels and types of reactivity. These and related species could be of some use in combinatorial solid and solution phase approaches to the development of PTK ligands and inhibitors with in vitro applications at least. The recent publication of a series of 3-PGK inhibitors by the Sheffield group ${ }^{36}$ signifies continuing interest in the area.

\section{Experimental}

All NMR spectra were obtained in $\mathrm{CDCl}_{3}$ and were recorded relative to tetramethylsilane as the internal standard. ${ }^{1} \mathrm{H}$ and ${ }^{13} \mathrm{C}$ NMR spectra were recorded on a Bruker AC-300 (300.13 and $75.47 \mathrm{MHz}$ respectively) spectrometer. ${ }^{13} \mathrm{C}$ NMR spectra were recorded using the JMOD pulse sequence. ${ }^{31} \mathrm{P}$ NMR spectra were also recorded on a Bruker AC-300 (121.50 MHz) spectrometer using orthophosphoric acid as the internal standard. ${ }^{19} \mathrm{~F}$ NMR spectra were recorded on a Bruker AC-300 $(282.41 \mathrm{MHz})$ relative to chlorotrifluoromethane as the internal standard. Chemical ionisation (CI) and electron impact (EI) mass spectra were recorded on a VG ProSpec mass spectrometer, a Kratos Profile mass spectrometer or a VG Zabspec mass spectrometer. Chemical ionisation (CI) methods used ammonia as the reagent gas. LC/MS were performed at
Table 3 Suzuki couplings of $6 \mathbf{a}^{a}$

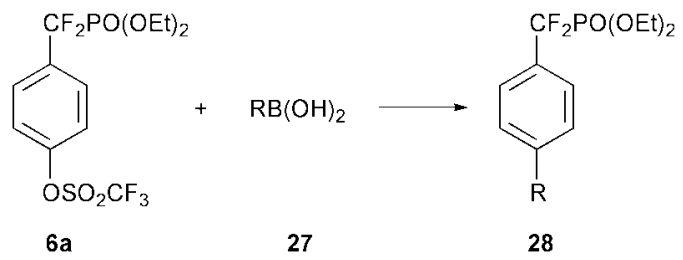

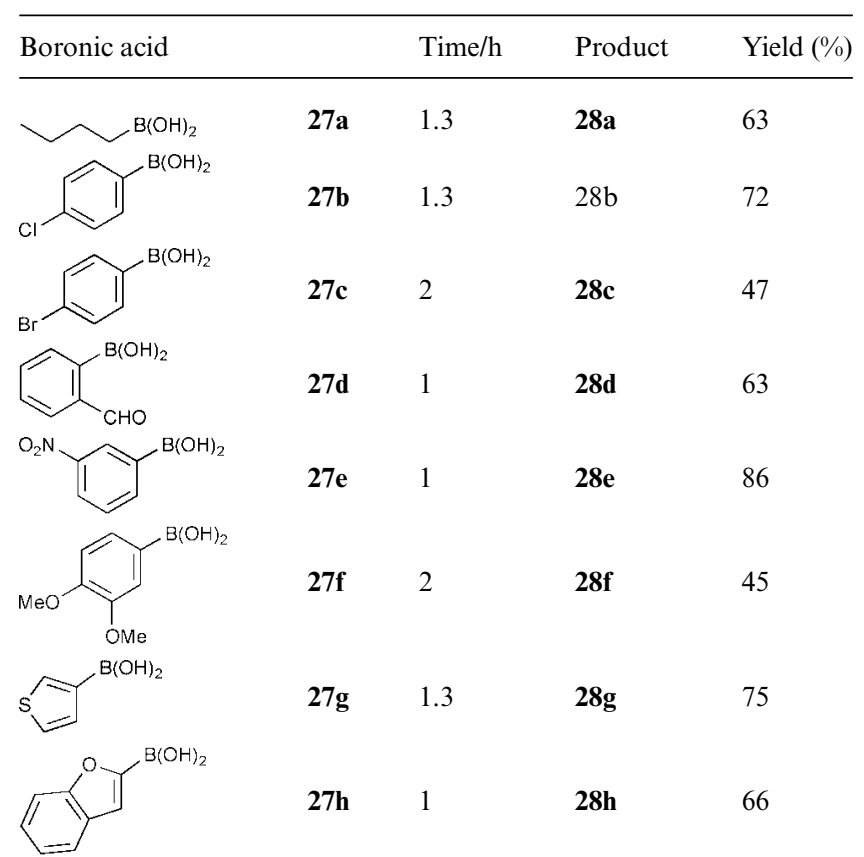

${ }^{a} 1.0$ equiv. 6a, 2.0 equiv. boronic acid, $5 \% \mathrm{Pd}\left(\mathrm{PPh}_{3}\right)_{4}, 4.0$ equiv. $\mathrm{Et}_{3} \mathrm{~N}$, DMF, $90{ }^{\circ} \mathrm{C}$

room temperature using an HP1050 HPLC (5 $\mu$ l injection volume; $3 \mu \mathrm{m} \mathrm{ABZ+PLUS} \mathrm{column} \mathrm{with} 3.3 \mathrm{~cm} \times 4.6 \mathrm{~mm}$ internal diameter) and a Platform Series II mass spectrometer. The HPLC ran a 5.50 minute solvent gradient (time taken to change from one solvent to another at the quoted flow rate) from formic acid to $10 \mathrm{mM}$ ammonium nitrate-acetonitrileformic acid $(10: 85: 5)$ with a flow rate of $3 \mathrm{ml} \mathrm{min}^{-1}$. A Micromass LCT mass spectrometer was used for both low resolution (ES-TOF) mass spectra and HRMS measurements (using a lockmass incorporated into the mobile phase). Elemental analyses were performed at the University of North London. For TLC, precoated aluminium-backed silica gel plates were supplied by E. Merck, A.G. Darmstadt, Germany (silica gel 60 F254, thickness $0.2 \mathrm{~mm}$, Art. 5554). Visualisation was achieved by UV light and/or an anisaldehyde-sulfuric acid or potassium permanganate stain. Flash column chromatography was performed using an air compressor on silica gel (E. Merck A.G. Kieselgel 60, Art. 9385). THF was dried by refluxing with benzophenone over sodium wire until a deep purple colour developed, then distilled and collected by dry syringe as required. Dimethylacetamide (DMA) was dried overnight with barium oxide then distilled under reduced pressure, and the distillate stored over calcium hydride under an atmosphere of nitrogen. Diisopropylamine and triethylamine were distilled from calcium hydride and each stored under an atmosphere of nitrogen over calcium hydride. Dimethylformamide was distilled from calcium hydride and stored over $4 \AA$ molecular sieves under an atmosphere of nitrogen.

Tetrakis(triphenylphosphino)palladium(0) and bis(triphenylphosphino)palladium(II) chloride were used as supplied by the Aldrich Chemical Co. Ltd. Zinc activation was achieved by heating the desired quantity of Aldrich 325 mesh zinc dust to $260^{\circ} \mathrm{C}$ under vacuum $(0.01 \mathrm{mmHg})$ for two hours. Sonication reactions were performed using a Kerry BE3118 ultrasonic 
bath operating at $50 \mathrm{~Hz}$. Iodotriflate 5a was prepared by a known method and gave spectral data in agreement with those reported. ${ }^{29}$

Boronic acids were purchased from Aldrich or Lancaster Synthesis; stannanes $\mathbf{2 1 b}-\mathbf{2 1 h}$ were generously provided by GlaxoWellcome. Copper bromide was prepared according to Vogel. $^{37}$

\section{4-[(Diethoxyphosphoryl)difluoromethyl]phenyl trifluoromethane- sulfonate $6 \mathrm{a}$}

Diethyl bromodifluoromethylphosphonate (28.4 mmol, $7.59 \mathrm{~g}$ ) in DMA $(7 \mathrm{ml})$ was added dropwise under nitrogen to a stirred solution of activated zinc dust $(28.4 \mathrm{mmol}, 1.85 \mathrm{~g})$ in DMA (7 $\mathrm{ml})$ at $50-60{ }^{\circ} \mathrm{C}$. After stirring the suspension at room temperature for 3 hours, $\mathrm{CuBr}$ (28.4 mmol, $4.06 \mathrm{~g}$ ) was added in one portion and stirring was continued for a further thirty minutes. A solution of 5a (14.2 mmol, $5.0 \mathrm{~g})$ in DMA (7 ml) was added dropwise and the reaction was sonicated for three hours, before being stirred at room temperature for a further 24 hours. The mixture was diluted with diethyl ether $(50 \mathrm{ml})$ and water $(30$ $\mathrm{ml})$, filtered through Celite $^{\circledR}$ and extracted with diethyl ether $(3 \times 30 \mathrm{ml})$. The combined organic extracts were washed with a saturated solution of $\mathrm{NaHCO}_{3}(5 \times 20 \mathrm{ml})$ and brine $(30 \mathrm{ml})$, dried $\left(\mathrm{MgSO}_{4}\right)$ and concentrated in vacuo to leave a pale yellow oil $(7.50 \mathrm{~g})$ which was purified by column chromatography $(30 \%$ ethyl acetate in light petroleum) to afford $6 \mathbf{a}(3.91 \mathrm{~g}, 66 \%)$ as a colourless oil; $R_{\mathrm{f}}(30 \%$ ethyl acetate in light petroleum) 0.53 (Found: C, 34.99; H, 3.47. $\mathrm{C}_{12} \mathrm{H}_{14} \mathrm{~F}_{5} \mathrm{O}_{6} \mathrm{PS}$ requires: $\mathrm{C}, 34.96 ; \mathrm{H}$, $3.42 \%) ; v_{\max }($ film $) / \mathrm{cm}^{-1} 2989 \mathrm{~m}, 1604 \mathrm{w}, 1504 \mathrm{~m}, 1428 \mathrm{~s}, 1274 \mathrm{~s}$ $(\mathrm{P}=\mathrm{O}), 1252 \mathrm{~s}, 1217 \mathrm{br}$ vs, $1142 \mathrm{vs}, 1020 \mathrm{br}$ vs, $889 \mathrm{~s}, 844 \mathrm{~m}, 757 \mathrm{~m}$; $\delta_{\mathrm{H}}\left(300 \mathrm{MHz}, \mathrm{CDCl}_{3}\right) 7.70(2 \mathrm{H}, \mathrm{d}, J 8, H-2, H-6), 7.36(2 \mathrm{H}$, d, $J 8, H-3, H-5), 4.28-4.09\left(4 \mathrm{H}, \mathrm{m},-\mathrm{OCH}_{2}\right), 1.31(6 \mathrm{H}, \mathrm{t}, J 7.4$, $\left.-\mathrm{CH}_{2} \mathrm{CH}_{3}\right) ; \delta_{\mathrm{C}}\left(75 \mathrm{MHz}, \mathrm{CDCl}_{3}\right) 151.0,133.1\left(\mathrm{dt},{ }^{2} J_{\mathrm{C}-\mathrm{F}} 22.3\right.$, $\left.{ }^{2} J_{\mathrm{C}-\mathrm{P}} 13.6\right), 128.6,121.5,118.9\left(\mathrm{q},{ }^{1} J_{\mathrm{C}-\mathrm{F}} 320.4\right), 117.5\left(\mathrm{dt},{ }^{1} J_{\mathrm{C}-\mathrm{F}}\right.$ $\left.263.9,{ }^{1} J_{\mathrm{C}-\mathrm{P}} 218.1\right), 65.0,16.2 ; \delta_{\mathrm{F}}\left(282 \mathrm{MHz}, \mathrm{CDCl}_{3}\right)-72.9(3 \mathrm{~F}$, $\mathrm{s}),-108.9\left(2 \mathrm{~F}, \mathrm{~d},{ }^{2} J_{\mathrm{F}-\mathrm{P}} 112.5\right) ; \delta_{\mathrm{P}}\left(121 \mathrm{MHz}, \mathrm{CDCl}_{3}\right) 5.83(\mathrm{t}$, $\left.{ }^{2} J_{\text {F-P }} 112.5\right)$ [HRMS (CI, M[NH $]_{4}^{+}$) Found: 430.051264. Calc. for $\mathrm{C}_{12} \mathrm{H}_{18} \mathrm{~F}_{5} \mathrm{NO}_{6} \mathrm{PS}$ : 430.052407]; $\mathrm{m} / \mathrm{z}$ (CI) $430 \quad(100 \%$, $\left.\mathrm{M}\left[\mathrm{NH}_{4}\right]^{+}\right), 413(15, \mathrm{M}+1), 282(75), 265$ (55).

\section{4-[(Diethoxyphosphoryl)difluoromethyl]phenyl nonafluoro- butanesulfonate $6 \mathrm{~b}$}

Activated zinc dust (1.30 g, $19.9 \mathrm{mmol})$ in DMA (5 ml), diethyl bromodifluoromethylphosphonate $(5.32 \mathrm{~g}, 19.9 \mathrm{mmol})$ in DMA (5 ml), copper bromide $(2.86 \mathrm{~g}, 19.9 \mathrm{mmol})$ and nonaflate $\mathbf{5 b}(5.00 \mathrm{~g}, 10.0 \mathrm{mmol})$ in DMA $(3 \mathrm{ml})$ were treated and worked up as described above. Concentration in vacuo afforded a yellow oil which was purified by column chromatography (light petroleum) to afford $\mathbf{6 b}(4.21 \mathrm{~g}, 75 \%)$ as a colourless oil (purity by GC 97\%); $R_{\mathrm{f}}$ (light petroleum) 0.42 (Found: C, 32.01; $\mathrm{H}, 2.51 . \mathrm{C}_{15} \mathrm{H}_{14} \mathrm{~F}_{11} \mathrm{O}_{6} \mathrm{PS}$ requires: $\left.\mathrm{C}, 32.04 ; \mathrm{H}, 2.51 \%\right) ; v_{\max }(\mathrm{film}) /$ $\mathrm{cm}^{-1} 2989 \mathrm{w}, 1503 \mathrm{~m}, 1430 \mathrm{~s}, 1354 \mathrm{~m}, 1242 \mathrm{br}$ vs $(\mathrm{P}=\mathrm{O}), 1205 \mathrm{vs}$, $1147 \mathrm{vs}, 1020 \mathrm{br}$ vs, $894 \mathrm{~s}, 844 \mathrm{~m}, 736 \mathrm{~m} ; \delta_{\mathrm{H}}\left(300 \mathrm{MHz}, \mathrm{CDCl}_{3}\right)$ $7.72(2 \mathrm{H}, \mathrm{d}, J 8.6, H-2, H-6), 7.37(2 \mathrm{H}, \mathrm{d}, J 8.6, H-3, H-5)$, $4.30-4.10\left(4 \mathrm{H}, \mathrm{m},-\mathrm{OCH}_{2}\right), 1.30\left(6 \mathrm{H}, \mathrm{t}, J 7.0,-\mathrm{CH}_{2} \mathrm{CH}_{3}\right) ; \delta_{\mathrm{C}}(75$ $\left.\mathrm{MHz}, \mathrm{CDCl}_{3}\right) 151.1,133.0\left(\mathrm{td},{ }^{2} J_{\mathrm{C}-\mathrm{F}} 22.6,{ }^{2} J_{\mathrm{C}-\mathrm{P}} 14.1\right), 128.4(\mathrm{td}$, $\left.{ }^{3} J_{\mathrm{C}-\mathrm{F}} 6.8,{ }^{3} J_{\mathrm{C}-\mathrm{P}} 2.3\right), 121.3,119.2-118.1(\mathrm{~m}), 117.2\left(\mathrm{td},{ }^{1} J_{\mathrm{C}-\mathrm{F}}\right.$ $\left.263.5,{ }^{1} J_{\mathrm{C}-\mathrm{P}} 217.6\right), 115.7-112.8(\mathrm{~m}), 112.2-108.0(\mathrm{~m}), 106.5$ $105.6(\mathrm{~m}), 65.0\left(\mathrm{~d},{ }^{2} J_{\mathrm{C}-\mathrm{P}} 7.4\right), 15.7\left(\mathrm{~d},{ }^{3} J_{\mathrm{C}-\mathrm{P}} 5.7\right) ; \delta_{\mathrm{F}}(282 \mathrm{MHz}$, $\left.\mathrm{CDCl}_{3}\right)-72.8\left(3 \mathrm{~F}, \mathrm{t},{ }^{3} J_{\mathrm{F}-\mathrm{F}} 9.5\right),-108.7\left(2 \mathrm{~F}, \mathrm{t},{ }^{2} J_{\mathrm{F}-\mathrm{F}} 12.7\right)$, -108.8 ( $\left.2 \mathrm{~F}, \mathrm{~d},{ }^{2} J_{\mathrm{F}-\mathrm{P}} 112.0\right),-120.86$ to -120.9 (2 F, m), -125.8 to $-125.9(2 \mathrm{~F}, \mathrm{~m}) ; \delta_{\mathrm{P}}\left(121 \mathrm{MHz}, \mathrm{CDCl}_{3}\right) 5.87\left(\mathrm{t},{ }^{2} J_{\mathrm{P}-\mathrm{F}}\right.$ 112.0) [HRMS (ES, M[Na] $]^{+}$) Found: 584.9987. Calc. for $\left.\mathrm{C}_{15} \mathrm{H}_{14} \mathrm{O}_{6} \mathrm{~F}_{11} \mathrm{NaPS}: 584.9971\right] ; \mathrm{m} / z(\mathrm{CI}) 580\left(61 \%, \mathrm{M}\left[\mathrm{NH}_{4}\right]^{+}\right) 563$ $(100, M+1), 425$ (7), 279 (7), 109 (7).

\section{4-[(Diisopropoxyphosphoryl)difluoromethyl]phenyl trifluoro- methanesulfonate $6 \mathrm{c}$}

Activated zinc dust $(1.30 \mathrm{~g}, 20 \mathrm{mmol})$ in DMF (10 ml), diiso- propyl bromodifluoromethylphosphonate $(5.90 \mathrm{~g}, 20 \mathrm{mmol})$ in DMF $(10 \mathrm{ml})$, copper bromide $(2.86 \mathrm{~g}, 20 \mathrm{mmol})$ and triflate $\mathbf{5 a}$ (3.52 g, $10.0 \mathrm{mmol}$ ) in DMF (2 ml) were treated and worked up as described above. Concentration in vacuo afforded a pale yellow oil which was purified by column chromatography $(30 \%$ diethyl ether in light petroleum) to afford $\mathbf{6 c}(1.36 \mathrm{~g}, 31 \%)$ as a colourless oil (purity by GC $96 \%) ; R_{\mathrm{f}}(30 \%$ ether in light petroleum) $0.17 ; v_{\max }($ film $) / \mathrm{cm}^{-1} 2986 \mathrm{~m}, 1604 \mathrm{w}, 1502 \mathrm{~m}, 1428 \mathrm{~s}, 1252 \mathrm{~m}$ $(\mathrm{P}=\mathrm{O}), 1215 \mathrm{~s}, 1143 \mathrm{~s}, 999 \mathrm{~s}, 887 \mathrm{~m} ; \delta_{\mathrm{H}}\left(300 \mathrm{MHz}, \mathrm{CDCl}_{3}\right) 7.71$ $(2 \mathrm{H}, \mathrm{d}, J 8.5, \mathrm{Ar}-H), 7.34(2 \mathrm{H}, \mathrm{d}, J 8.5, \mathrm{Ar}-H), 4.83-4.69(2 \mathrm{H}$, m, - $\left.\mathrm{CH}\left(\mathrm{CH}_{3}\right)_{2}\right), 1.33\left(6 \mathrm{H}, \mathrm{d}, J 6.2,-\mathrm{CH}\left(\mathrm{CH}_{3}\right)_{2}\right), 1.23(6 \mathrm{H}, \mathrm{d}$, $\left.J 6.2,-\mathrm{CH}\left(\mathrm{CH}_{3}\right)_{2}\right) ; \delta_{\mathrm{C}}\left(75 \mathrm{MHz}, \mathrm{CDCl}_{3}\right) 150.9,133.4\left(\mathrm{dt},{ }^{2} J_{\mathrm{C}-\mathrm{F}}\right.$ $\left.22.6,{ }^{2} J_{\mathrm{C}-\mathrm{P}} 14.1\right), 128.8,121.4,118.7$ (q, $\left.{ }^{1} J_{\mathrm{C}-\mathrm{F}} 320.5\right), 117.1(\mathrm{dt}$, $\left.{ }^{1} J_{\mathrm{C}-\mathrm{F}} 263.9,{ }^{1} J_{\mathrm{C}-\mathrm{P}} 219.3\right), 74.3,74.2,24.1,24.0,23.5,23.4 ; \delta_{\mathrm{F}}(282$ $\left.\mathrm{MHz}, \mathrm{CDCl}_{3}\right)-72.9(3 \mathrm{~F}, \mathrm{~s}),-109.4\left(2 \mathrm{~F}, \mathrm{~d},{ }^{2} J_{\mathrm{F}-\mathrm{P}} 112.5\right) ; \delta_{\mathrm{P}}(121$ $\mathrm{MHz}, \mathrm{CDCl}_{3}$ ) 4.07 (t, ${ }^{2} J_{\text {F-P }}$ 112.5) [HRMS (ES, M[Na] $]^{+}$) Found: 463.0376. Calc. for $\mathrm{C}_{14} \mathrm{H}_{18} \mathrm{~F}_{5} \mathrm{NaO}_{6} \mathrm{PS}$ : 463.0380]; $\mathrm{m} / \mathrm{z}$ $\left(\mathrm{ES}^{+}\right) 463\left(90 \%, \mathrm{M}[\mathrm{Na}]^{+}\right), 421(82), 379(100)$.

\section{3-[(Diethoxyphosphoryl)difluoromethyl]-1-methoxybenzene 8}

From diethyl bromodifluoromethylphosphonate $(6.41 \mathrm{mmol}$, $1.71 \mathrm{~g})$ in DMA (2 ml), activated zinc dust (6.41 mmol, $0.42 \mathrm{~g})$ in DMA (2 ml), CuBr (6.41 mmol, $0.92 \mathrm{~g}), 3$-iodoanisole (4.27 mmol, $1.00 \mathrm{~g})$ in DMA $(2 \mathrm{ml})$ which were reacted and worked up as described above. Concentration in vacuo afforded a yellow oil $(2.30 \mathrm{~g})$ which was purified by column chromatography $(20 \%$ ethyl acetate in light petroleum) to afford $\mathbf{8}(0.40 \mathrm{~g}, 32 \%)$ as a colourless oil; $R_{\mathrm{f}}(20 \%$ ethyl acetate in light petroleum) 0.2 (Found: $\mathrm{C}, 49.11$; $\mathrm{H}, 5.76 . \mathrm{C}_{12} \mathrm{H}_{17} \mathrm{~F}_{2} \mathrm{O}_{4} \mathrm{P}$ requires: $\mathrm{C}$, 48.99; $\mathrm{H}$, $5.82 \%) ; v_{\max }($ film $) / \mathrm{cm}^{-1} 2985 \mathrm{~s}, 1604 \mathrm{~s}, 1588 \mathrm{~s}, 1488 \mathrm{~s}, 1454 \mathrm{~s}, 1438 \mathrm{~s}$, $1275 \mathrm{vs}(\mathrm{P}=\mathrm{O}), 1211 \mathrm{~s}, 1043 \mathrm{br}$ vs, 794s, $749 \mathrm{~m}, 698 \mathrm{~s}, 682 \mathrm{~m} ; \delta_{\mathrm{H}}(300$ $\left.\mathrm{MHz}, \mathrm{CDCl}_{3}\right) 7.32(1 \mathrm{H}, \mathrm{dd}, J$ 8.1, 7.7, H-5), $7.16(1 \mathrm{H}, \mathrm{d}, J 7.7$, $H-4), 7.09$ (1 H, s, H-2), $6.97(1 \mathrm{H}, \mathrm{d}, J$ 8.1,H-6), 4.25-4.03 $\left(4 \mathrm{H}, \mathrm{m},-\mathrm{OCH}_{2}\right), 3.78\left(3 \mathrm{H}, \mathrm{s},-\mathrm{OCH}_{3}\right), 1.27(6 \mathrm{H}, \mathrm{t}, J 7.0$, $\left.-\mathrm{CH}_{2} \mathrm{CH}_{3}\right) ; \delta_{\mathrm{C}}\left(75 \mathrm{MHz}, \mathrm{CDCl}_{3}\right) 159.7,134.2\left(\mathrm{dt},{ }^{2} J_{\mathrm{C}-\mathrm{F}} 22.0\right.$, $\left.{ }^{2} J_{\mathrm{C}-\mathrm{P}} 14.1\right), 129.8,118.7\left(\mathrm{dt}, J 7.3,{ }^{3} J_{\mathrm{C}-\mathrm{P}} 2.8\right), 118.5,118.2(\mathrm{dt}$, $\left.{ }^{1} J_{\mathrm{C}-\mathrm{F}} 263.4,{ }^{1} J_{\mathrm{C}-\mathrm{P}} 218.1\right), 111.8\left(\mathrm{dt},{ }^{3} J_{\mathrm{C}-\mathrm{F}} 7.4,{ }^{3} J_{\mathrm{C}-\mathrm{P}} 2.3\right), 65.0(\mathrm{~d}$, $\left.{ }^{2} J_{\mathrm{C}-\mathrm{P}} 6.4\right), 55.5,16.5\left(\mathrm{~d},{ }^{3} J_{\mathrm{C}-\mathrm{P}} 5.0\right) ; \delta_{\mathrm{F}}\left(282 \mathrm{MHz}, \mathrm{CDCl}_{3}\right)-108.2$ $\left(2 \mathrm{~F}, \mathrm{~d},{ }^{2} J_{\mathrm{F}-\mathrm{P}} 116.9\right) ; \delta_{\mathrm{P}}\left(121 \mathrm{MHz}, \mathrm{CDCl}_{3}\right) 5.31\left(\mathrm{t},{ }^{2} J_{\mathrm{F}-\mathrm{P}} 116.9\right)$ [HRMS (CI, M + 1) Found: 295.090726. Calc. for $\left.\mathrm{C}_{12} \mathrm{H}_{18} \mathrm{~F}_{2} \mathrm{O}_{4} \mathrm{P}: 295.091079\right] ; \mathrm{m} / z(\mathrm{CI}) 312\left(72 \%, \mathrm{M}\left[\mathrm{NH}_{4}\right]^{+}\right), 295$ $(100, \mathrm{M}+1), 157(20)$.

\section{4-[(Diethoxyphosphoryl)difluoromethyl]-1-methoxybenzene 9}

Aryl difluorophosphonate 9 was prepared under identical conditions to 8 from 4-iodoanisole $(4.27 \mathrm{mmol}, 1.00 \mathrm{~g})$ and diethyl bromodifluoromethylphosphonate $(6.41 \mathrm{mmol}, 1.71 \mathrm{~g})$ to leave a yellow oil $(2.30 \mathrm{~g})$ which was purified by column chromatography ( $20 \%$ ethyl acetate in light petroleum) to afford 9 $(0.21 \mathrm{~g}, 17 \%)$ as a colourless oil; $R_{\mathrm{f}}(20 \%$ ethyl acetate in light petroleum) 0.21 (Found: $\mathrm{C}, 48.99 ; \mathrm{H}$, 5.75. $\mathrm{C}_{12} \mathrm{H}_{17} \mathrm{~F}_{2} \mathrm{O}_{4} \mathrm{P}$ requires: C, 48.99; $\mathrm{H}, 5.82 \%) ; v_{\max }(\mathrm{film}) / \mathrm{cm}^{-1} 2985 \mathrm{~m}, 1614 \mathrm{~s}$, $1516 \mathrm{~s}, 1254 \mathrm{~s}(\mathrm{P}=\mathrm{O}), 1019 \mathrm{br} \mathrm{s}, 835 \mathrm{~m} ; \delta_{\mathrm{H}}\left(300 \mathrm{MHz}, \mathrm{CDCl}_{3}\right)$ $7.51(2 \mathrm{H}, \mathrm{d}, J 8.5, H-3, H-5), 6.91(2 \mathrm{H}, \mathrm{d}, J 8.5, H-2, H-6)$, $4.244 .01\left(4 \mathrm{H}, \mathrm{m},-\mathrm{OC} H_{2}\right), 3.78\left(3 \mathrm{H}, \mathrm{s},-\mathrm{OCH}_{3}\right), 1.26(6 \mathrm{H}, \mathrm{t}$, $J$ 7.0, $\left.-\mathrm{CH}_{2} \mathrm{CH}_{3}\right) ; \delta_{\mathrm{C}}\left(75 \mathrm{MHz}, \mathrm{CDCl}_{3}\right) 161.4,127.8,124.5$ $\left(\mathrm{dt},{ }^{2} J_{\mathrm{C}-\mathrm{F}} 22.6,{ }^{2} J_{\mathrm{C}-\mathrm{P}} 14.1\right), 118.2\left(\mathrm{dt},{ }^{1} J_{\mathrm{C}-\mathrm{F}} 262.8,{ }^{1} J_{\mathrm{C}-\mathrm{P}} 221.0\right)$, $113.8,64.7\left(\mathrm{~d},{ }^{2} J_{\mathrm{C}-\mathrm{P}} 6.4\right), 55.3,16.4\left(\mathrm{~d},{ }^{3} J_{\mathrm{C}-\mathrm{P}} 5.0\right) ; \delta_{\mathrm{F}}(282 \mathrm{MHz}$, $\left.\mathrm{CDCl}_{3}\right)-107.1\left(\mathrm{~d},{ }^{2} J_{\mathrm{F}-\mathrm{P}} 119.5\right) ; \delta_{\mathrm{P}}\left(121 \mathrm{MHz}, \mathrm{CDCl}_{3}\right) 6.95$ (t, ${ }^{2} J_{\mathrm{P}-\mathrm{F}}$ 119.5) [HRMS (CI, M + 1) Found: 295.091284. Calc. for $\left.\mathrm{C}_{12} \mathrm{H}_{18} \mathrm{~F}_{2} \mathrm{O}_{4} \mathrm{P}: 295.091079\right] ; m / z$ (CI) $295(39 \%, \mathrm{M}+1), 275$ (10), 221 (7), 157 (100).

\section{Benzyl (2-hydroxy-5-iodo)benzoate 11}

Benzyl bromide $(4.5 \mathrm{ml}, 37.9 \mathrm{mmol})$ and potassium fluoride $(4.84 \mathrm{~g}, 83.3 \mathrm{mmol})$ were dissolved in DMF $(50 \mathrm{ml})$ with stirring at room temperature. After 5 minutes, 5-iodosalicylic acid $\mathbf{1 0}$ $(10.00 \mathrm{~g}, 37.9 \mathrm{mmol})$ was added in one portion and the mixture was heated to $100{ }^{\circ} \mathrm{C}$ and stirred at that temperature for 2 hours 
under an atmosphere of nitrogen. The mixture was cooled to room temperature, quenched with water $(50 \mathrm{ml})$ and extracted with diethyl ether $(3 \times 75 \mathrm{ml})$. The combined organic extracts were washed with water $(3 \times 100 \mathrm{ml})$ and brine $(100 \mathrm{ml})$, dried $\left(\mathrm{MgSO}_{4}\right)$ and concentrated in vacuo to afford a light pink solid $(13.62 \mathrm{~g})$ which was recrystallised from light petroleum to afford 11 as a white solid $(11.04 \mathrm{~g}, 82 \%) ; \mathrm{mp} 50-53{ }^{\circ} \mathrm{C}$ (light petroleum); $R_{\mathrm{f}}(40 \%$ diethyl ether in light petroleum) 0.77 (Found: C, 47.38; H, 2.98. $\mathrm{C}_{14} \mathrm{H}_{11} \mathrm{IO}_{3}$ requires: $\mathrm{C}, 47.48 ; \mathrm{H}$, $3.13 \%) ; v_{\max }(\mathrm{KBr}) / \mathrm{cm}^{-1} 3462 \mathrm{~m}, 1675 \mathrm{~s}, 1602 \mathrm{~m}, 1470 \mathrm{~m}, 1286 \mathrm{~s}$, $1201 \mathrm{~s}, 1091 \mathrm{~m}, 694 \mathrm{~m} ; \delta_{\mathrm{H}}\left(300 \mathrm{MHz}, \mathrm{CDCl}_{3}\right) 8.14(1 \mathrm{H}, \mathrm{d}, J 2.2$, $H-6), 7.74(1 \mathrm{H}, \mathrm{dd}, J 8.8, J 2.2, H-4), 7.46-7.36(5 \mathrm{H}, \mathrm{m}, \mathrm{Ph}-H)$, $6.77(1 \mathrm{H}, \mathrm{d}, J 8.8, H-3), 5.38\left(2 \mathrm{H}, \mathrm{s},-\mathrm{OCH}_{2} \mathrm{Ph}\right) ; \delta_{\mathrm{C}}(75 \mathrm{MHz}$, $\left.\mathrm{CDCl}_{3}\right)$ 168.8, 161.4, 144.2, 138.2, 134.9, 128.8, 128.5, 120.0, 114.6, 80.1, 67.5; $\mathrm{m} / \mathrm{z}$ (EI) $354\left(20 \%\right.$, [M] $\left.{ }^{+}\right), 91$ (100). The phenolic $\mathrm{O}-\mathrm{H}$ was not observed in the ${ }^{1} \mathrm{H}$ NMR spectrum.

\section{Benzyl (5-iodo-2-trifluoromethylsulfonyloxy)benzoate 12}

Trifluoromethanesulfonic anhydride $(5.3 \mathrm{ml}, 31.5 \mathrm{mmol})$ was added dropwise to a cooled (ice-water bath) solution of benzyl (2-hydroxy-5-iodo)benzoate 11 (10.14 g, $28.6 \mathrm{mmol})$ in pyridine $(20 \mathrm{ml})$. The reaction mixture was stirred for 18 hours at $0{ }^{\circ} \mathrm{C}$. The resulting yellow mixture was diluted with water $(50 \mathrm{ml})$ and extracted with diethyl ether $(3 \times 50 \mathrm{ml})$. The combined organic extracts were washed with water $(3 \times 100 \mathrm{ml})$ and brine $(100$ $\mathrm{ml})$, dried $\left(\mathrm{MgSO}_{4}\right)$ and concentrated in vacuo to recover a yellow oil which was purified by column chromatography $(15 \%$ diethyl ether in light petroleum) to afford $\mathbf{1 2}(11.01 \mathrm{~g}, 79 \%)$ as a pale yellow liquid (purity by GC $99 \%) ; R_{\mathrm{f}}(15 \%$ diethyl ether in light petroleum) 0.39 (Found: $\mathrm{C}, 37.19 ; \mathrm{H}, 1.98 . \mathrm{C}_{15} \mathrm{H}_{10} \mathrm{O}_{5} \mathrm{~F}_{3} \mathrm{SI}$ requires: $\mathrm{C}, 37.06 ; \mathrm{H}, 2.07 \%) ; v_{\max }(\mathrm{film}) / \mathrm{cm}^{-1} 3034 \mathrm{w}, 1731 \mathrm{vs}$ $(\mathrm{C}=\mathrm{O}), 1594 \mathrm{~m}, 1474 \mathrm{~s}, 1428 \mathrm{vs}, 1286 \mathrm{vs}, 1250 \mathrm{vs}(\mathrm{P}=\mathrm{O}), 1213 \mathrm{vs}$, $1170 v s, 1140 \mathrm{vs}, 1072 \mathrm{~s}, 889 \mathrm{~s}, 832 \mathrm{~s}, 749 \mathrm{~s}, 609 \mathrm{~s} ; \delta_{\mathrm{H}}(300 \mathrm{MHz}$, $\left.\mathrm{CDCl}_{3}\right) 8.36(1 \mathrm{H}, \mathrm{d}, J 2.2, H-6), 7.91(1 \mathrm{H}, \mathrm{dd}, J 8.8,2.2, H-4)$, 7.47-7.36 (5 H, m, PhH), $7.03(1 \mathrm{H}, \mathrm{d}, J 8.8, H-3), 5.40(2 \mathrm{H}, \mathrm{s}$, $\left.-\mathrm{OCH}_{2} \mathrm{Ph}\right) ; \delta_{\mathrm{C}}\left(75 \mathrm{MHz}, \mathrm{CDCl}_{3}\right) 162.2,148.2,143.2,141.4$, $134.9,129.0,128.7,126.1,124.6,118.7$ (q, $\left.{ }^{1} J_{\mathrm{C}-\mathrm{F}} 320.8\right), 92.9$, $68.1 ; \delta_{\mathrm{F}}\left(282 \mathrm{MHz}, \mathrm{CDCl}_{3}\right)-73.1$ (s) [HRMS (FAB, $\mathrm{M}+\mathrm{Na}^{+}$) Found: 508.9159. Calc. for $\mathrm{C}_{15} \mathrm{H}_{10} \mathrm{O}_{5} \mathrm{~F}_{3} \mathrm{SINa}$ : 508.9144]; $\mathrm{m} / \mathrm{z}$ (EI) $486\left(44 \%,[\mathrm{M}]^{+}\right), 379(80), 359$ (66) 247 (53), 91 (100).

\section{Benzyl 5-[(diethoxyphosphoryl)difluoromethyl]-2-(trifluoro- methylsulfonyloxy)benzoate 13}

From diethyl bromodifluoromethylphosphonate $(0.55 \mathrm{~g}, 2.1$ mmol) in DMA $(2 \mathrm{ml})$, activated zinc dust $(0.13 \mathrm{~g}, 2.1 \mathrm{mmol})$ in dry DMA $(2 \mathrm{ml})$, freshly prepared copper(I) bromide $(0.30 \mathrm{~g}$, $2.1 \mathrm{mmol}), 12(0.50 \mathrm{~g}, 1.0 \mathrm{mmol})$ in DMA $(2 \mathrm{ml})$, reacted and worked up as described above. Concentration in vacuo afforded a yellow oil $(0.81 \mathrm{~g})$ which was purified by column chromatography (60\% diethyl ether in light petroleum) to afford $\mathbf{1 3}$ $(0.37 \mathrm{~g}, 67 \%)$ as a pale yellow oil (purity by GC $100 \%)$; $v_{\max }($ film $) / \mathrm{cm}^{-1} 2986 \mathrm{~m}, 1735(\mathrm{C}=\mathrm{O}), 1431 \mathrm{vs}, 1276 \mathrm{vs}(\mathrm{P}=\mathrm{O})$, $1224 \mathrm{vs}, 1140 \mathrm{vs}, 1070 \mathrm{vs}, 1022 \mathrm{vs}, 893 \mathrm{~s}, 752 \mathrm{~s}, 699 \mathrm{~m} ; \delta_{\mathrm{H}}(300 \mathrm{MHz}$, $\left.\mathrm{CDCl}_{3}\right) 8.29(1 \mathrm{H}, \mathrm{s}, H-6), 7.87(1 \mathrm{H}, \mathrm{d}, J 8.8, H-3), 7.47-7.34$ $(6 \mathrm{H}, \mathrm{m}), 5.42\left(2 \mathrm{H}, \mathrm{s},-\mathrm{OC} \mathrm{H}_{2} \mathrm{Ph}\right), 4.28-4.15\left(4 \mathrm{H}, \mathrm{m},-\mathrm{OCH}_{2}\right)$, $1.29\left(6 \mathrm{H}, \mathrm{t}, J 7.2,-\mathrm{CH}_{2} \mathrm{CH}_{3}\right) ; \delta_{\mathrm{C}}\left(75 \mathrm{MHz}, \mathrm{CDCl}_{3}\right) 162.8$, $149.8,134.9,133.4\left(\mathrm{td},{ }^{2} J_{\mathrm{C}-\mathrm{F}} 23.2,{ }^{2} J_{\mathrm{C}-\mathrm{P}} 14.1\right), 132.4\left(\mathrm{td},{ }^{3} J_{\mathrm{C}-\mathrm{F}} 6.8\right.$, $\left.{ }^{3} J_{\mathrm{C}-\mathrm{P}} 2.3\right), 130.8\left(\mathrm{td},{ }^{3} J_{\mathrm{C}-\mathrm{F}} 6.8,{ }^{3} J_{\mathrm{C}-\mathrm{P}} 2.3\right), 128.9,128.7,124.9$, $123.3,118.7\left(\mathrm{q},{ }^{1} J_{\mathrm{C}-\mathrm{F}} 320.4\right), 116.9\left(\mathrm{td},{ }^{1} J_{\mathrm{C}-\mathrm{F}} 264.3,{ }^{1} J_{\mathrm{C}-\mathrm{P}} 218.0\right)$, $68.0,65.2\left(\mathrm{~d},{ }^{2} J_{\mathrm{C}-\mathrm{P}} 6.8\right), 16.3\left(\mathrm{~d},{ }^{3} J_{\mathrm{C}-\mathrm{P}} 5.7\right) ; \delta_{\mathrm{F}}(121 \mathrm{MHz}$, $\left.\mathrm{CDCl}_{3}\right)-73.1(3 \mathrm{~F}, \mathrm{~s}),-109.1\left(2 \mathrm{~F}, \mathrm{~d},{ }^{2} J_{\mathrm{F}-\mathrm{P}} 111.6\right) ; \delta_{\mathrm{P}}(121 \mathrm{MHz}$, $\left.\mathrm{CDCl}_{3}\right) 5.38\left(\mathrm{t},{ }^{2} J_{\mathrm{P}-\mathrm{F}}\right.$ 111.6) [HRMS (FAB, $\mathrm{M}+\mathrm{Na}^{+}$) Found: 569.0429. Calc. for $\mathrm{C}_{19} \mathrm{H}_{20} \mathrm{~F}_{5} \mathrm{O}_{8} \mathrm{PNa}$ : 569.0434]; $\mathrm{m} / \mathrm{z}$ (EI) 546 $\left(16 \%,[\mathrm{M}]^{+}\right), 439$ (35), 412 (85), 307 (64), 91 (100).

\section{4-Benzyloxy-3-iodo-5-methoxybenzaldehyde 14}

A solution of 5-iodovanillin (5.65 mmol, $1.57 \mathrm{~g})$ in DMF (2 ml) was added dropwise under an atmosphere of nitrogen to a stirred suspension of potassium carbonate $(5.65 \mathrm{mmol}, 0.78 \mathrm{~g})$ in DMF $(2 \mathrm{ml})$ at $0{ }^{\circ} \mathrm{C}$. The suspension was stirred at $0{ }^{\circ} \mathrm{C}$ for 50 minutes. Benzyl bromide $(5.65 \mathrm{mmol}, 0.67 \mathrm{ml})$ was added dropwise and after stirring at $0{ }^{\circ} \mathrm{C}$ for a further 30 minutes, the reaction was allowed to warm to room temperature and stirred for four hours. Water $(10 \mathrm{ml})$ was added and the mixture was extracted with diethyl ether $(3 \times 15 \mathrm{ml})$. The combined organic extracts were washed with brine $(10 \mathrm{ml})$, dried $\left(\mathrm{MgSO}_{4}\right)$ and concentrated in vacuo to leave a yellow oil (2.46 g) which was purified by column chromatography $(20 \%$ diethyl ether in light petroleum) to afford $14(1.85 \mathrm{~g}, 89 \%)$ as an off white solid; $\mathrm{mp} 54-56^{\circ} \mathrm{C} ; R_{\mathrm{f}}(20 \%$ diethyl ether in light petroleum $) 0.24$; $v_{\max }(\mathrm{KBr}) / \mathrm{cm}^{-1} 2984 \mathrm{~m}, 1694 \mathrm{~s}(\mathrm{C}=\mathrm{O}), 1583 \mathrm{~s}, 1560 \mathrm{~s}, 1464 \mathrm{~s}, 1275 \mathrm{~s}$ $(\mathrm{P}=\mathrm{O}), 1143 \mathrm{~s}, 1042 \mathrm{~s}, 954 \mathrm{~s}, 738 \mathrm{~m}, 692 \mathrm{~s}, 671 \mathrm{~m} ; \delta_{\mathrm{H}}(300 \mathrm{MHz}$, $\left.\mathrm{CDCl}_{3}\right) 9.82(1 \mathrm{H}, \mathrm{s}, \mathrm{CHO}), 7.84(1 \mathrm{H}, \mathrm{d}, J 1.8$, Ar- $H), 7.58-$ $7.51(2 \mathrm{H}, \mathrm{m}, \mathrm{Ar}-H), 7.44-7.30(4 \mathrm{H}, \mathrm{m}, \mathrm{Ar}-H), 5.14(2 \mathrm{H}, \mathrm{s}$, $\left.-\mathrm{OCH}_{2} \mathrm{Ph}\right), 3.93\left(3 \mathrm{H}, \mathrm{s},-\mathrm{OCH}_{3}\right) ; \delta_{\mathrm{C}}\left(75 \mathrm{MHz}, \mathrm{CDCl}_{3}\right) 189.8$, 153.1, 152.9, 136.5, 134.9, 134.0, 128.7, 128.5, 111.0, 92.8, 74.8, 56.2. This material was used directly without further purification or characterisation.

\section{4-Benzyloxy-3-[(diethoxyphosphoryl)difluoromethyl]-5- methoxybenzaldehyde 16}

From diethyl bromodifluoromethylphosphonate $(3.05 \mathrm{mmol}$, $0.82 \mathrm{~g})$ in DMA ( $2 \mathrm{ml})$, activated zinc dust $(3.05 \mathrm{mmol}, 0.20 \mathrm{~g})$ in DMA ( $2 \mathrm{ml})$, freshly prepared $\mathrm{CuBr}(3.05 \mathrm{mmol}, 0.44 \mathrm{~g}), 14$ $(2.04 \mathrm{mmol}, 0.75 \mathrm{~g})$ in DMA $(2 \mathrm{ml})$, reacted for 40 hours and worked up as described above. Concentration in vacuo afforded a yellow oil $(1.76 \mathrm{~g})$ which was purified by column chromatography (40\% ethyl acetate in light petroleum) to afford $\mathbf{1 6}$ $(0.22 \mathrm{~g}, 25 \%)$ as a colourless oil; $R_{\mathrm{f}}(40 \%$ ethyl acetate in light petroleum) $0.33 ; v_{\max }($ film $) / \mathrm{cm}^{-1} 2984 \mathrm{~m}, 1698 \mathrm{~s}(\mathrm{C}=\mathrm{O}), 1586 \mathrm{~m}$, $1291 \mathrm{br} \mathrm{s}(\mathrm{P}=\mathrm{O}), 1020 \mathrm{br} \mathrm{s} ; \delta_{\mathrm{H}}\left(300 \mathrm{MHz}, \mathrm{CDCl}_{3}\right) 9.91(1 \mathrm{H}, \mathrm{s}$, $\mathrm{CHO}), 7.65(1 \mathrm{H}, \mathrm{s}, H-2), 7.58(1 \mathrm{H}, \mathrm{s}, H-6), 7.52(2 \mathrm{H}, \mathrm{d}, J$ 6.6, Ar- $H)$, 7.41-7.29 (3 H, m, Ar- $H$ ), 5.15 (2 H, s, $\left.-\mathrm{OCH}_{2} \mathrm{Ph}\right), 4.30$ $4.04\left(4 \mathrm{H}, \mathrm{m},-\mathrm{OCH}_{2} \mathrm{CH}_{3}\right), 3.96\left(3 \mathrm{H}, \mathrm{s},-\mathrm{OCH}_{3}\right), 1.20(6 \mathrm{H}, \mathrm{t}$, $J$ 7.7, $\left.-\mathrm{CH}_{2} \mathrm{CH}_{3}\right) ; \delta_{\mathrm{C}}\left(75 \mathrm{MHz}, \mathrm{CDCl}_{3}\right) 190.6,154.3,151.9$, $136.9,132.2,128.5,128.3,128.2,127.9-127.4(\mathrm{~m}), 124.6\left(\mathrm{t},{ }^{3} J_{\mathrm{C}-\mathrm{F}}\right.$ $8.2), 118.0\left(\mathrm{dt},{ }^{1} J_{\mathrm{C}-\mathrm{F}} 264.5,{ }^{1} J_{\mathrm{C}-\mathrm{P}} 218.7\right), 112.2,75.8,65.0\left(\mathrm{~d},{ }^{2} J_{\mathrm{C}-\mathrm{P}}\right.$ 6.2), 56.2, 16.3 (d, $\left.{ }^{3} J_{\mathrm{C}-\mathrm{P}} 5.7\right) ; \delta_{\mathrm{F}}\left(282 \mathrm{MHz}, \mathrm{CDCl}_{3}\right)-105.1(\mathrm{~d}$, $\left.{ }^{2} J_{\mathrm{F}-\mathrm{P}} 113.2\right) ; \delta_{\mathrm{P}}\left(121 \mathrm{MHz}, \mathrm{CDCl}_{3}\right) 5.93\left(\mathrm{t},{ }^{2} J_{\mathrm{P}-\mathrm{F}} 113.2\right)$ [HRMS $\left(\mathrm{CI}, \mathrm{M}[\mathrm{H}]^{+}\right)$Found: 429.126534. Calc. for $\mathrm{C}_{20} \mathrm{H}_{24} \mathrm{~F}_{2} \mathrm{O}_{6} \mathrm{P}$ : 429.127859]; $m / z$ (CI) 429 (24\%, M $\left.{ }^{+}\right), 401$ (13), 339 (9), 262 (8), 245 (100).

\section{2-Benzyloxy-3,5-diiodobenzaldehyde 15}

Benzyl ether $\mathbf{1 5}$ was prepared under identical conditions to $\mathbf{1 4}$ from 3,5-diiodosalicylaldehyde ( $8.02 \mathrm{mmol}, 3.00 \mathrm{~g})$ and benzyl bromide $(8.02 \mathrm{mmol}, 0.95 \mathrm{ml})$ to afford a yellow solid which was recrystallised from diethyl ether-light petroleum to afford $15(3.71 \mathrm{~g}, 100 \%)$ as an off white solid; $\mathrm{mp} 98-101{ }^{\circ} \mathrm{C} ; \delta_{\mathrm{H}}(300$ $\left.\mathrm{MHz}, \mathrm{CDCl}_{3}\right) 9.91(1 \mathrm{H}, \mathrm{s}, \mathrm{CHO}), 8.37$ (1 H, d, J 2.1, H-6), 8.06 (1 H, d, J 2.1, H-4), 7.47-7.36 (5 H, m, Ar- $H), 5.05(2 \mathrm{H}, \mathrm{s})$; $\delta_{\mathrm{C}}\left(75 \mathrm{MHz}, \mathrm{CDCl}_{3}\right) 187.7,160.7,152.7,137.7,134.7,132.0$, $129.2,129.0,128.9,94.9,89.6,78.6$. The material was used directly without further purification or characterisation.

\section{2-Benzyloxy-3-[(diethoxyphosphoryl)difluoromethyl]-5-iodo- benzaldehyde 17a and 2-benzyloxy-5-[(diethoxyphosphoryl)- difluoromethyl]-3-iodobenzaldehyde 17b}

From diethyl bromodifluoromethylphosphonate $(4.85 \mathrm{mmol}$, $1.30 \mathrm{~g})$ in DMA (2 ml), activated zinc dust ( $4.85 \mathrm{mmol}, 0.32 \mathrm{~g})$ in DMA (2 ml), freshly prepared $\mathrm{CuBr}(4.85 \mathrm{mmol}, 0.69 \mathrm{~g})$, and $16(3.23 \mathrm{mmol}, 1.50 \mathrm{~g})$ in DMA (2 ml) which were reacted and worked up as described above. Concentration in vacuo afforded a yellow oil ( $2.87 \mathrm{~g})$ which was purified by column chromatography $(30 \%$ ethyl acetate in light petroleum) to afford the aryl phosphonates $17 \mathbf{a}(0.32 \mathrm{~g}, 19 \%)$ and $\mathbf{1 7 b}(0.35 \mathrm{~g}, 21 \%)$ as 
colourless oils; for 17 a $R_{\mathrm{f}}(30 \%$ ethyl acetate in light petroleum) $0.30 ; v_{\max }(\mathrm{film}) / \mathrm{cm}^{-1} 2984 \mathrm{~s}, 1693 \mathrm{vs}(\mathrm{C}=\mathrm{O}), 1571 \mathrm{~s}, 1445 \mathrm{~s}, 1372 \mathrm{~s}$, 1272 vs $(\mathrm{P}=\mathrm{O}), 1234 \mathrm{vs}, 1021 \mathrm{br}$ vs, $736 \mathrm{~s}, 699 \mathrm{~s}, 660 \mathrm{~m} ; \delta_{\mathrm{H}}(300$ $\left.\mathrm{MHz}, \mathrm{CDCl}_{3}\right) 10.05(1 \mathrm{H}, \mathrm{s}, \mathrm{CHO}), 8.29(1 \mathrm{H}, \mathrm{s}, H-6), 8.01(1 \mathrm{H}$, s, H-4), 7.49-7.35 (5 H, m, $\left.\mathrm{CH}_{2} \mathrm{Ph}\right), 5.10\left(2 \mathrm{H}, \mathrm{s}, \mathrm{OCH}_{2} \mathrm{Ph}\right), 4.34$ $4.16\left(4 \mathrm{H}, \mathrm{m},-\mathrm{OCH}_{2}\right), 1.34\left(6 \mathrm{H}, \mathrm{t},{ }^{3} \mathrm{~J}_{\mathrm{H}-\mathrm{H}} 7.0 \mathrm{~Hz},-\mathrm{CH}_{2} \mathrm{CH}_{3}\right)$; $\delta_{\mathrm{C}}\left(75 \mathrm{MHz}, \mathrm{CDCl}_{3}\right) 188.1,162.6,143.1\left(\mathrm{t},{ }^{3} J_{\mathrm{C}-\mathrm{F}} 5.6\right), 134.7$, $131.2\left(\mathrm{dt},{ }^{2} J_{\mathrm{C}-\mathrm{F}} 23.2,{ }^{2} J_{\mathrm{C}-\mathrm{P}} 14.1\right), 130.4,129.2,129.0,128.9,127.2$ $\left(\mathrm{t},{ }^{3} J_{\mathrm{C}-\mathrm{F}} 5.1\right), 116.6\left(\mathrm{dt},{ }^{1} J_{\mathrm{C}-\mathrm{F}} 265.6,{ }^{1} J_{\mathrm{C}-\mathrm{P}} 218.7\right), 93.6,78.5,64.5$ $\left(\mathrm{d},{ }^{2} J_{\mathrm{C}-\mathrm{P}} 6.8\right), 16.4\left(\mathrm{~d},{ }^{3} J_{\mathrm{C}-\mathrm{P}} 5.7\right) ; \delta_{\mathrm{F}}\left(282 \mathrm{MHz}, \mathrm{CDCl}_{3}\right)-108.7$ $\left(\mathrm{d},{ }^{2} J_{\mathrm{F}-\mathrm{P}} 113.5\right) ; \delta_{\mathrm{P}}\left(121 \mathrm{MHz}, \mathrm{CDCl}_{3}\right) 5.57\left(\mathrm{t},{ }^{2} J_{\mathrm{P}-\mathrm{F}} 113.5\right)$ [HRMS (FAB ${ }^{+}$) Found: 546.993790 . Calc. for $\mathrm{C}_{19} \mathrm{H}_{20} \mathrm{~F}_{2} \mathrm{INaO}_{5} \mathrm{P}$ : 546.995891]; $m / z$ (EI) $524\left(19 \%, \mathrm{M}^{+}\right), 496$ (9), 433 (26), 397 (9), 91 (100); for $\mathbf{1 7 b} R_{\mathrm{f}}(30 \%$ ethyl acetate in light petroleum) 0.40 ; $\delta_{\mathrm{H}}\left(300 \mathrm{MHz}, \mathrm{CDCl}_{3}\right) 10.06(1 \mathrm{H}, \mathrm{s}, \mathrm{CHO}), 8.22(1 \mathrm{H}, \mathrm{s}, H-6)$, $8.07(1 \mathrm{H}, \mathrm{s}, H-4), 7.45-7.32\left(5 \mathrm{H}, \mathrm{m}, \mathrm{CH}_{2} P h\right), 5.04(2 \mathrm{H}, \mathrm{s}$, $\left.-\mathrm{OCH}_{2} \mathrm{Ph}\right), 4.24-4.06\left(4 \mathrm{H}, \mathrm{m},-\mathrm{OCH}_{2}\right), 1.20\left(6 \mathrm{H}, \mathrm{t},{ }^{3} J_{\mathrm{H}-\mathrm{H}} 7.0\right.$, $\left.-\mathrm{CH}_{2} \mathrm{CH}_{3}\right) ; \delta_{\mathrm{C}}\left(75 \mathrm{MHz}, \mathrm{CDCl}_{3}\right) 187.0,159.6,142.8\left(\mathrm{t},{ }^{3} J_{\mathrm{C}-\mathrm{F}}\right.$ $8.2), 140.5,135.0,132.5,129.6\left(\mathrm{dt},{ }^{2} J_{\mathrm{C}-\mathrm{F}} 22.0,{ }^{2} J_{\mathrm{C}-\mathrm{P}} 13.0\right), 128.8$, $128.6,128.5,117.1\left(\mathrm{dt},{ }^{1} J_{\mathrm{C}-\mathrm{F}} 266.5,{ }^{1}{ }^{\mathrm{C}-\mathrm{P}} \mathrm{2} 218.7\right), 88.0,81.7,65.1$ $\left(\mathrm{d},{ }^{2} J_{\mathrm{C}-\mathrm{P}} 6.8\right), 16.2\left(\mathrm{~d},{ }^{3} J_{\mathrm{C}-\mathrm{P}} 5.7\right) ; \delta_{\mathrm{F}}\left(282 \mathrm{MHz}, \mathrm{CDCl}_{3}\right)-105.7$ $\left(\mathrm{d},{ }^{2} J_{\mathrm{F}-\mathrm{P}} 111.6\right) ; \delta_{\mathrm{P}}\left(121 \mathrm{MHz}, \mathrm{CDCl}_{3}\right) 5.44\left(\mathrm{t},{ }^{2} J_{\mathrm{P}-\mathrm{F}} 111.6\right)$ [HRMS (FAB ${ }^{+}$) Found: 546.994831. Calc. for $\mathrm{C}_{19} \mathrm{H}_{20} \mathrm{~F}_{2} \mathrm{INaO}_{5} \mathrm{P}$ : 546.995891]; $m / z\left(\mathrm{FAB}^{+}\right) 547\left(100 \%, \mathrm{M}[\mathrm{Na}]^{+}\right), 392(6)$.

\section{2-[(Diethoxyphosphoryl)difluoromethyl]thiophene 19}

From diethyl bromodifluoromethylphosphonate $(7.14 \mathrm{mmol}$, $1.91 \mathrm{~g})$ in DMA (3 ml), activated zinc dust $(7.14 \mathrm{mmol}, 0.46 \mathrm{~g})$ in DMA (3 ml), freshly prepared $\mathrm{CuBr}(7.14 \mathrm{mmol}, 1.05 \mathrm{~g})$ and 2-iodothiophene $(4.76 \mathrm{mmol}, 0.53 \mathrm{ml})$ in DMA (3 ml) which were reacted and worked up as described above. Concentration in vacuo afforded a yellow oil (1.95 g) which was purified by column chromatography ( $40 \%$ diethyl ether in light petroleum) to afford $19(0.79 \mathrm{~g}, 62 \%)$ as a colourless oil; $R_{\mathrm{f}}(40 \%$ diethyl ether in light petroleum) 0.48 (Found: $\mathrm{C}, 40.09 ; \mathrm{H}, 5.00$. $\mathrm{C}_{9} \mathrm{H}_{13} \mathrm{~F}_{2} \mathrm{O}_{3}$ PS requires: $\left.\mathrm{C}, 40.00 ; \mathrm{H}, 4.85 \%\right) ; v_{\max }($ film $) / \mathrm{cm}^{-1}$ $2987 \mathrm{~m}, 1431 \mathrm{~m}, 1272 \mathrm{~s}(\mathrm{P}=\mathrm{O}), 1242 \mathrm{~s}, 1036 \mathrm{br}$ vs, $717 \mathrm{~m} ; \delta_{\mathrm{H}}(300$ $\left.\mathrm{MHz}, \mathrm{CDCl}_{3}\right) 7.53-7.39(2 \mathrm{H}, \mathrm{m}, H-2, H-4), 7.10-7.04(1 \mathrm{H}, \mathrm{m}$, $H-3), 4.30-4.12\left(4 \mathrm{H}, \mathrm{m},-\mathrm{OCH}_{2}\right), 1.31\left(6 \mathrm{H}, \mathrm{t},{ }^{3} J_{\mathrm{H}-\mathrm{H}} 7.0 \mathrm{~Hz}\right.$, $\left.\mathrm{CH}_{2} \mathrm{CH}_{3}\right) ; \delta_{\mathrm{C}}\left(75 \mathrm{MHz}, \mathrm{CDCl}_{3}\right) 133.7\left(\mathrm{dt},{ }^{2} J_{\mathrm{C}-\mathrm{F}} 26.0,{ }^{2} J_{\mathrm{C}-\mathrm{P}} 17.0\right)$, $128.9,128.8,127.2,97.9\left(\mathrm{dt},{ }^{1} J_{\mathrm{C}-\mathrm{F}} 261.1,{ }^{1} J_{\mathrm{C}-\mathrm{P}} 225.5\right), 65.0(\mathrm{~d}$, $\left.{ }^{2} J_{\mathrm{C}-\mathrm{P}} 6.4\right), 16.2\left(\mathrm{~d},{ }^{3} J_{\mathrm{C}-\mathrm{P}} 4.8\right) ; \delta_{\mathrm{F}}\left(282 \mathrm{MHz}, \mathrm{CDCl}_{3}\right)-96.9(2 \mathrm{~F}, \mathrm{~d}$, $\left.{ }^{2} J_{\text {F-P }} 114.4\right) ; \delta_{\mathrm{P}}\left(121 \mathrm{MHz}, \mathrm{CDCl}_{3}\right) 5.41\left(\mathrm{t},{ }^{2} J_{\mathrm{F}-\mathrm{P}} 114.4\right)$ [HRMS (CI) Found: 271.038054. Calc. for $\mathrm{C}_{9} \mathrm{H}_{14} \mathrm{~F}_{2} \mathrm{O}_{3} \mathrm{PS}$ : 271.036936]; $\mathrm{m} / \mathrm{z}(\mathrm{CI}) 288\left(10 \%, \mathrm{M}\left[\mathrm{NH}_{4}\right]^{+}\right), 271(82, \mathrm{M}+1), 270(9), 251$ (14), 155 (25), 133 (100).

General procedure for Stille couplings from iodide 2 or triflate $6 \mathbf{a}$ : 1-\{4'-[(diethoxyphosphoryl)difluoromethyl $]$ phenyl\}ethene 22a

$\mathrm{PdCl}_{2}\left(\mathrm{PPh}_{3}\right)_{2}(0.4 \mathrm{mmol}, 0.27 \mathrm{~g})$ was added to a stirred solution of iodide 2 (7.69 mmol, $3.0 \mathrm{~g})$ and tributylstannylethene 21a $(8.07 \mathrm{mmol}, 2.56 \mathrm{~g})$ in DMF $(15 \mathrm{ml})$ and the mixture was heated to $60^{\circ} \mathrm{C}$ for one hour. After cooling, the black suspension was diluted with water $(15 \mathrm{ml})$ and ether $(25 \mathrm{ml})$, and filtered through a pad of Harbolite ${ }^{\circledR}$. The mixture was extracted with ether $(3 \times 20 \mathrm{ml})$, and the combined organic extracts were washed with brine $(20 \mathrm{ml})$. After drying $\left(\mathrm{MgSO}_{4}\right)$, the solvent was removed in vacuo to leave a brown oil $(3.24 \mathrm{~g})$ which was purified by flash chromatography $(30 \%$ ethyl acetate in light petroleum) to afford alkene $22 \mathrm{a}(1.87 \mathrm{~g}, 84 \%)$ as a colourless oil; $R_{\mathrm{F}}(40 \%$ ethyl acetate in light petroleum) 0.57 (Found: C, 53.72; $\mathrm{H}, 6.03$. Calc. for $\left.\mathrm{C}_{13} \mathrm{H}_{17} \mathrm{~F}_{2} \mathrm{O}_{3} \mathrm{P}: \mathrm{C}, 53.80 ; \mathrm{H}, 5.90 \%\right) ; v_{\max }($ film)/ $\mathrm{cm}^{-1} 2985 \mathrm{~m}, 1261 \mathrm{~s}(\mathrm{P}=\mathrm{O}), 1017 \mathrm{~s}, 843 \mathrm{~m} ; \delta_{\mathrm{H}}\left(300 \mathrm{MHz}, \mathrm{CDCl}_{3}\right)$ $7.56\left(2 \mathrm{H}, \mathrm{d}, J 8.1, H-2^{\prime}, H-6^{\prime}\right), 7.47\left(2 \mathrm{H}, \mathrm{d}, J 8.1, H-3^{\prime}, H-5^{\prime}\right)$, $6.72(1 \mathrm{H}, \mathrm{dd}, J 17.3,11.0, H-1), 5.81\left(1 \mathrm{H}, \mathrm{d}, J_{\text {trans }} 17.3, H-2\right)$, $5.33\left(1 \mathrm{H}, \mathrm{d}, J_{\text {cis }} 11.0, \mathrm{H}-2\right), 4.28-4.06\left(4 \mathrm{H}, \mathrm{m},-\mathrm{OCH}_{2}\right), 1.30$ $\left(6 \mathrm{H}, \mathrm{t},{ }^{3} J_{\mathrm{H}-\mathrm{H}} 7.0, \mathrm{CH}_{2} \mathrm{CH}_{3}\right) ; \delta_{\mathrm{C}}\left(75 \mathrm{MHz}, \mathrm{CDCl}_{3}\right) 140.7,135.9$, $131.7\left(\mathrm{dt},{ }^{2} J_{\text {C-F }} 22.0,{ }^{2} J_{\text {C-P }} 13.6\right), 126.5\left(\mathrm{dt},{ }^{3} J_{\mathrm{C}-\mathrm{F}} 5.9,{ }^{3} J_{\text {C-P }} 1.7\right)$, $126.2,118.1\left(\mathrm{dt},{ }^{1} J_{\mathrm{C}-\mathrm{F}} 263.4,{ }^{1} J_{\mathrm{C}-\mathrm{P}} 218.7\right), 115.9,64.8\left(\mathrm{~d},{ }^{2} J_{\mathrm{C}-\mathrm{P}}\right.$
$6.8), 16.4\left(\mathrm{~d},{ }^{3} J_{\mathrm{C}-\mathrm{P}} 5.7\right) ; \delta_{\mathrm{F}}\left(282 \mathrm{MHz}, \mathrm{CDCl}_{3}\right)-108.3\left(\mathrm{~d},{ }^{2} J_{\mathrm{F}-\mathrm{P}}\right.$ $117.0) ; \delta_{\mathrm{P}}\left(121 \mathrm{MHz}, \mathrm{CDCl}_{3}\right) 6.70\left(\mathrm{t},{ }^{2} \mathrm{~J}_{\mathrm{P}-\mathrm{F}} 117.0\right) ; \mathrm{m} / \mathrm{z}$ (CI) 308 $\left(100 \%, \mathrm{M}\left[\mathrm{NH}_{4}\right]^{+}\right), 291(21, \mathrm{M}+1)$.

1-\{4'-[(Diethoxyphosphoryl)difluoromethyl]phenyl\}-1-ethoxyethene 22b and $1-\left\{4^{\prime}-[(\right.$ diethoxyphosphoryl)difluoromethyl]phenyl\}ethanone 23. As above from 6a $(1 \mathrm{mmol}, 0.41 \mathrm{~g})$ and 1-(tributylstannyl)-1-ethoxyethene $21 \mathrm{~b}(1 \mathrm{mmol}, 0.36 \mathrm{~g})$. Following the usual work up, the residue (crude 22b) was redissolved in THF $(6 \mathrm{ml})$. Dilute $\mathrm{HCl}(3 \mathrm{ml}$ of $1 \mathrm{M}$ solution) was added and the mixture was stirred at room temperature for 3 hours. After extraction with ether $(3 \times 10 \mathrm{ml})$, the combined organic extracts were washed with $\mathrm{NaHCO}_{3}(2 \times 7 \mathrm{ml})$ and brine $(5 \mathrm{ml})$, dried $\left(\mathrm{MgSO}_{4}\right)$ and concentrated in vacuo to leave a yellow oil $(0.23 \mathrm{~g})$ which was purified by flash column chromatography (30\% ethyl acetate in light petroleum) to afford the aryl ketone $23(0.16 \mathrm{~g}, 52 \%)$ as a colourless oil; $R_{\mathrm{f}}(40 \%$ ethyl acetate in light petroleum) 0.39 (Found: $\mathrm{C}, 51.26 ; \mathrm{H}, 5.50$. $\mathrm{C}_{13} \mathrm{H}_{17} \mathrm{~F}_{2} \mathrm{O}_{4} \mathrm{P}$ requires: $\left.\mathrm{C}, 50.99 ; \mathrm{H}, 5.59 \%\right) ; \delta_{\mathrm{H}}(300 \mathrm{MHz}$, $\left.\mathrm{CDCl}_{3}\right) 7.98\left(2 \mathrm{H}, \mathrm{d}, J 8.1, H-2^{\prime}, H-6^{\prime}\right), 7.67\left(2 \mathrm{H}, \mathrm{d}, J 8.1, H-3^{\prime}\right.$, $\left.H-5^{\prime}\right), 4.27-4.0\left(4 \mathrm{H}, \mathrm{m},-\mathrm{OCH}_{2}\right), 2.59\left(3 \mathrm{H}, \mathrm{s}, \mathrm{CH}_{3} \mathrm{CO}\right), 1.27$ $\left(6 \mathrm{H}, \mathrm{t},{ }^{3} \mathrm{~J}_{\mathrm{H}-\mathrm{H}} 7.0, \mathrm{CH}_{2} \mathrm{CH}_{3}\right) ; \delta_{\mathrm{C}}\left(75 \mathrm{MHz}, \mathrm{CDCl}_{3}\right) 197.2,138.6$, $136.7\left(\mathrm{dt},{ }^{2} J_{\mathrm{C}-\mathrm{F}} 22.0,{ }^{2} J_{\mathrm{C}-\mathrm{P}} 13.6\right), 128.6,126.5\left(\mathrm{dt},{ }^{3} J_{\mathrm{C}-\mathrm{F}} 5.7\right), 117.5$ $\left(\mathrm{dt},{ }^{1} J_{\mathrm{C}-\mathrm{F}} 263.9,{ }^{1} J_{\mathrm{C}-\mathrm{P}} 217.0\right), 64.8\left(\mathrm{~d},{ }^{2} J_{\mathrm{C}-\mathrm{P}} 6.8\right), 26.6,16.4(\mathrm{~d}$, $\left.{ }^{3} J_{\mathrm{C}-\mathrm{P}} 5.1\right) ; \delta_{\mathrm{F}}\left(282 \mathrm{MHz}, \mathrm{CDCl}_{3}\right)-109.4\left(\mathrm{~d},{ }^{2} J_{\mathrm{F}-\mathrm{P}} 113.5\right) ; \delta_{\mathrm{P}}(121$ $\left.\mathrm{MHz}, \mathrm{CDCl}_{3}\right) 6.02\left(\mathrm{t},{ }^{2} J_{\mathrm{P}-\mathrm{F}} 113.5\right)$ [HRMS (CI, M $\left.\left[\mathrm{NH}_{4}\right]^{+}\right)$ Found: 324.117480. Calc. for $\left.\mathrm{C}_{13} \mathrm{H}_{21} \mathrm{~F}_{2} \mathrm{NO}_{4} \mathrm{P}: 324.117628\right] ; \mathrm{m} / \mathrm{z}$ (EI) $306\left(25 \%, \mathrm{M}^{+}\right), 291$ (27), 264 (31), 169 (97), 155 (100), 141 (47), 126 (80), 109 (94).

4-(2'-Pyridyl)-1-[(diethoxyphosphoryl)difluoromethyl]benzene 22c. As above from 6a $(1 \mathrm{mmol}, 0.41 \mathrm{~g})$ and 2-(tributylstannyl)pyridine 21c ( $1 \mathrm{mmol}, 0.37 \mathrm{~g})$. Following the usual work up, purification by flash chromatography ( $40 \%$ ethyl acetate in light petroleum) afforded $22 \mathrm{c}(0.18 \mathrm{~g}, 52 \%)$ as a colourless oil; $R_{\mathrm{f}}\left(40 \%\right.$ ethyl acetate in light petroleum) $0.25 ; v_{\max }(\mathrm{film}) / \mathrm{cm}^{-1}$ $2959 \mathrm{~m}, 1702 \mathrm{w}, 1587 \mathrm{~m}, 1467 \mathrm{~s}, 1436 \mathrm{~s}, 1259 \mathrm{vs}(\mathrm{P}=\mathrm{O}), 1019 \mathrm{vs}$, $783 \mathrm{~s} ; \delta_{\mathrm{H}}\left(300 \mathrm{MHz}, \mathrm{CDCl}_{3}\right) 8.69\left(1 \mathrm{H}, \mathrm{d}, J 4.8, H-6^{\prime}\right), 8.07(2 \mathrm{H}$, d, $J$ 8.1, H-2, H-6), 7.79-7.64 (4 H, m, H-3,H-5, H-4'), 7.30$7.23(1 \mathrm{H}, \mathrm{m}, H-5), 4.30-4.10\left(4 \mathrm{H}, \mathrm{m},-\mathrm{OCH}_{2}\right), 1.31(6 \mathrm{H}, \mathrm{t}, J 7.0$, $\left.-\mathrm{CH}_{2} \mathrm{CH}_{3}\right) ; \delta_{\mathrm{C}}\left(75 \mathrm{MHz}, \mathrm{CDCl}_{3}\right) 150.1,149.7,141.5,136.8$, $132.8\left(\mathrm{dt},{ }^{2} J_{\mathrm{C}-\mathrm{F}} 22.0,{ }^{2} J_{\mathrm{C}-\mathrm{P}} 13.6\right), 126.8,126.6\left(\mathrm{t},{ }^{3} J_{\mathrm{C}-\mathrm{F}} 5.1\right), 122.6$, $120.7,117.9\left(\mathrm{dt},{ }^{1} J_{\mathrm{C}-\mathrm{F}} 262.8,{ }^{1} J_{\mathrm{C}-\mathrm{P}} 218.1\right), 64.7\left(\mathrm{~d},{ }^{2} J_{\mathrm{C}-\mathrm{P}} 6.8\right), 16.2$ $\left(\mathrm{d},{ }^{3} J_{\mathrm{C}-\mathrm{P}} 5.7\right) ; \delta_{\mathrm{F}}\left(282 \mathrm{MHz}, \mathrm{CDCl}_{3}\right)-108.5\left(\mathrm{~d},{ }^{2} J_{\mathrm{F}-\mathrm{P}} 117.0\right)$; $\delta_{\mathrm{P}}\left(121 \mathrm{MHz}, \mathrm{CDCl}_{3}\right) 6.61\left(\mathrm{t},{ }^{2} J_{\mathrm{P}-\mathrm{F}} 117.0\right)$ [HRMS (ES, M[Na] $\left.{ }^{+}\right)$ Found: 364.0883. Calc. for $\mathrm{C}_{16} \mathrm{H}_{18} \mathrm{~F}_{2} \mathrm{NNaO}_{3} \mathrm{P}$ : 364.0890]; $\mathrm{m} / \mathrm{z}$ (LCMS, CI, $4.30 \mathrm{~min}) 342$ (100\%, M + 1), 322 (3), 314 (23).

\section{4-(2'-Furyl)-1-[(diethoxyphosphoryl)difluoromethyl]benzene} 22d. As above from 6a (1 mmol, $0.41 \mathrm{~g}$ ) and 2-(tributylstannyl)furan $21 \mathrm{~d}$ ( $1 \mathrm{mmol}, 0.36 \mathrm{~g})$. Following the usual work up, purification by flash chromatography $(30 \%$ ethyl acetate in light petroleum) afforded the furyl benzene derivative $22 \mathrm{~d}(0.26 \mathrm{~g}$, $79 \%)$ as a colourless oil; $R_{\mathrm{f}}(40 \%$ ethyl acetate in light petroleum) $0.50 ; v_{\max }(\mathrm{film}) / \mathrm{cm}^{-1} 2987 \mathrm{~m}, 1770 \mathrm{~m}, 1731 \mathrm{~m}, 1693 \mathrm{~m}$, $1409 \mathrm{~m}, 1258 \mathrm{~s}(\mathrm{P}=\mathrm{O}), 1022 \mathrm{br} \mathrm{s}, 839 \mathrm{~m}, 794 \mathrm{~m}, 750 \mathrm{~m} ; \delta_{\mathrm{H}}(300$ $\left.\mathrm{MHz}, \mathrm{CDCl}_{3}\right) 7.70(2 \mathrm{H}, \mathrm{d}, J$ 8.1, H-2, H-6), $7.58(2 \mathrm{H}, \mathrm{d}, J 8.1$, $H-3, H-5), 7.44\left(1 \mathrm{H}, \mathrm{d}, J 1.8, H-5^{\prime}\right), 6.69\left(1 \mathrm{H}, \mathrm{d}, J 3.7, H-3^{\prime}\right)$, 6.44 (1 H, dd, J 3.7, 1.8, H-4'), 4.26-4.11 (4 H, m, -OCH $), 1.26$ $\left(6 \mathrm{H}, \mathrm{t}, J\right.$ 7.0, $\left.-\mathrm{CH}_{2} \mathrm{CH}_{3}\right) ; \delta_{\mathrm{C}}\left(75 \mathrm{MHz}, \mathrm{CDCl}_{3}\right) 152.8,142.9$, $133.0,131.0\left(\mathrm{dt},{ }^{2} J_{\mathrm{C}-\mathrm{F}} 22.0,{ }^{2} J_{\mathrm{C}-\mathrm{P}} 13.6\right), 126.7\left(\mathrm{dt},{ }^{3} J_{\mathrm{C}-\mathrm{F}} 5.4,{ }^{3} J_{\mathrm{C}-\mathrm{P}}\right.$ $1.7), 123.6,118.0\left(\mathrm{dt},{ }^{1} J_{\mathrm{C}-\mathrm{F}} 263.4,{ }^{1} J_{\mathrm{C}-\mathrm{P}} 219.3\right), 111.9,106.6,64.8$ $\left(\mathrm{d},{ }^{2} J_{\mathrm{C}-\mathrm{P}} 6.2\right), 16.3\left(\mathrm{~d},{ }^{3} J_{\mathrm{C}-\mathrm{P}} 5.7\right) ; \delta_{\mathrm{F}}\left(282 \mathrm{MHz}, \mathrm{CDCl}_{3}\right)-108.4$ $\left(\mathrm{d},{ }^{2} J_{\mathrm{F}-\mathrm{P}} 117.0\right) ; \delta_{\mathrm{P}}\left(121 \mathrm{MHz}, \mathrm{CDCl}_{3}\right) 6.64\left(\mathrm{t},{ }^{2} J_{\mathrm{P}-\mathrm{F}} 117.0\right)$ [HRMS (ES, M[Na] $]^{+}$) Found: 353.0718. Calc. for $\mathrm{C}_{15} \mathrm{H}_{17} \mathrm{~F}_{2^{-}}$ $\mathrm{NaO}_{4} \mathrm{P}:$ 353.0730]; $\mathrm{m} / \mathrm{z}$ (LCMS, CI, $\left.4.62 \mathrm{~min}\right) 331(28 \%$, M + 1), 311 (100), 283 (12), 219 (27).

2-\{4'-[(Diethoxyphosphoryl)difluoromethyl $]$ phenyl $\}-5-(1,3-$ dioxolan-2-yl)furan 22e. As above from triflate $\mathbf{6 a}(1 \mathrm{mmol}$, 
$0.41 \mathrm{~g})$ and 2-(tributylstannyl)-5-(1,3-dioxolan-2-yl)furan 21e $(1 \mathrm{mmol}, 0.43 \mathrm{~g})$. Following the usual work up, purification by flash chromatography ( $40 \%$ ethyl acetate in light petroleum) afforded 22e $(0.24 \mathrm{~g}, 60 \%)$ as a yellow oil; $R_{\mathrm{f}}(40 \%$ ethyl acetate in light petroleum) $0.21 ; \delta_{\mathrm{H}}\left(300 \mathrm{MHz}, \mathrm{CDCl}_{3}\right) 7.71(2 \mathrm{H}, \mathrm{d}$, $\left.J 8.1, H-3^{\prime}, H-5^{\prime}\right), 7.58\left(2 \mathrm{H}, \mathrm{d}, J 8.1, H-2^{\prime}, H-6^{\prime}\right), 6.67(1 \mathrm{H}, \mathrm{d}$, $J 3.3, H-4), 6.67(1 \mathrm{H}, \mathrm{d}, J 3.3, H-3), 5.95\left(1 \mathrm{H}, \mathrm{s}, \mathrm{CHO}_{2}\right), 4.28$ $3.90\left(8 \mathrm{H}, \mathrm{m},-\mathrm{OCH}_{2} \mathrm{CH}_{3},-\mathrm{OCH}_{2} \mathrm{CH}_{2}\right), 1.29(6 \mathrm{H}, \mathrm{t}, J$ 7.0, $\left.-\mathrm{CH}_{2} \mathrm{CH}_{3}\right) ; \delta_{\mathrm{C}}\left(75 \mathrm{MHz}, \mathrm{CDCl}_{3}\right) 153.3,151.6,133.3\left(\mathrm{dt},{ }^{2} J_{\mathrm{C}-\mathrm{F}}\right.$ $\left.22.6,{ }^{2} J_{\mathrm{C}-\mathrm{P}} 13.6\right), 132.7,126.6\left(\mathrm{t},{ }^{3} J_{\mathrm{C}-\mathrm{F}} 4.5\right), 123.8,117.9\left(\mathrm{dt},{ }^{1} J_{\mathrm{C}-\mathrm{F}}\right.$ $\left.262.8,{ }^{1} J_{\mathrm{C}-\mathrm{P}} 218.1\right), 110.8,107.0,97.7,65.2,65.0\left(\mathrm{~d},{ }^{2} J_{\mathrm{C}-\mathrm{P}} 6.8\right)$, $16.3\left(\mathrm{~d},{ }^{3} J_{\mathrm{C}-\mathrm{P}} 5.7\right) ; \delta_{\mathrm{F}}\left(282 \mathrm{MHz}, \mathrm{CDCl}_{3}\right)-108.6\left(\mathrm{~d},{ }^{2} J_{\mathrm{F}-\mathrm{P}} 117.0\right)$; $\delta_{\mathrm{P}}\left(121 \mathrm{MHz}, \mathrm{CDCl}_{3}\right) 6.59\left(\mathrm{t},{ }^{2} J_{\mathrm{P}-\mathrm{F}} 117.0\right) ; \mathrm{m} / \mathrm{z}(\mathrm{LCMS}, \mathrm{CI}, 4.48$ min) $403(100 \%, M+1), 383$ (75), 291 (27), 243 (37). The acetal was hydrolysed without further characterisation.

\section{2-\{4'-[(Diethoxyphosphoryl)difluoromethyl]phenyl\}-5-furan-}

carbaldehyde 24 . Aqueous $\mathrm{HCl}(2.0 \mathrm{ml}$ of a $2 \mathrm{M}$ solution) was added to a stirred solution of acetal $22 \mathrm{e}(0.97 \mathrm{mmol}, 0.39 \mathrm{~g})$ in THF $(6 \mathrm{ml})$. After stirring at room temperature for twenty minutes the mixture was diluted with water $(3 \mathrm{ml})$, and extracted with ether $(3 \times 6 \mathrm{ml})$. The combined organic extracts were washed with $\mathrm{NaHCO}_{3}(2 \times 5 \mathrm{ml})$ and brine $(5 \mathrm{ml})$, dried $\left(\mathrm{MgSO}_{4}\right)$ and concentrated in vacuo to leave a yellow oil $(0.36 \mathrm{~g})$ which was purified by column chromatography $(40 \%$ diethyl ether in isohexane to $100 \%$ ether) to afford aldehyde $24(0.25 \mathrm{~g}$, $77 \%)$ as a yellow solid; $\mathrm{mp} 67-69{ }^{\circ} \mathrm{C} ; R_{\mathrm{f}}(40 \%$ ethyl acetate in isohexane) 0.13 (Found: $\mathrm{C}, 53.54 ; \mathrm{H}, 4.76 . \mathrm{C}_{16} \mathrm{H}_{17} \mathrm{~F}_{2} \mathrm{O}_{5} \mathrm{P}$ requires: $\mathrm{C}, 53.64 ; \mathrm{H}, 4.78 \%) ; v_{\max }(\mathrm{KBr}) / \mathrm{cm}^{-1} 2958 \mathrm{~m}, 1725 \mathrm{~m}$, $1678 \mathrm{vs}(\mathrm{C}=\mathrm{O}), 1668 \mathrm{~s}, 1485 \mathrm{~m}, 1254 \mathrm{vs}(\mathrm{P}=\mathrm{O}), 1024 \mathrm{br}$ vs, $807 \mathrm{~m}$, $773 \mathrm{~m} ; \delta_{\mathrm{H}}\left(300 \mathrm{MHz}, \mathrm{CDCl}_{3}\right) 9.67(1 \mathrm{H}, \mathrm{s}, \mathrm{CHO}), 7.89(2 \mathrm{H}, \mathrm{d}$, $J$ 8.5, H-3',$\left.H-5^{\prime}\right), 7.65\left(2 \mathrm{H}, \mathrm{d}, J 8.5, H-2^{\prime}, H-6^{\prime}\right), 7.33(1 \mathrm{H}, \mathrm{d}$, $J 3.7, H-4), 6.92(1 \mathrm{H}, \mathrm{d}, J 3.7, H-3), 4.30-4.08\left(4 \mathrm{H}, \mathrm{m},-\mathrm{OCH}_{2}\right)$, $1.31\left(6 \mathrm{H}, \mathrm{t}, J 7.0,-\mathrm{CH}_{2} \mathrm{CH}_{3}\right) ; \delta_{\mathrm{C}}\left(75 \mathrm{MHz}, \mathrm{CDCl}_{3}\right) 177.4,157.8$, $152.3,133.4\left(\mathrm{dt},{ }^{2} J_{\mathrm{C}-\mathrm{F}} 22.0,{ }^{2} J_{\mathrm{C}-\mathrm{P}} 13.6\right), 131.1,126.9\left(\mathrm{t},{ }^{3} J_{\mathrm{C}-\mathrm{F}} 5.9\right)$, $125.1,123.3,117.7\left(\mathrm{dt},{ }^{1} J_{\mathrm{C}-\mathrm{F}} 263.6,{ }^{1} J_{\mathrm{C}-\mathrm{P}} 218.1\right), 108.9,64.9(\mathrm{~d}$, $\left.{ }^{2} J_{\mathrm{C}-\mathrm{P}} 6.8\right), 16.3\left(\mathrm{~d},{ }^{3} J_{\mathrm{C}-\mathrm{P}} 5.1\right) ; \delta_{\mathrm{F}}\left(282 \mathrm{MHz}, \mathrm{CDCl}_{3}\right)-109.0(\mathrm{~d}$, $\left.{ }^{2} J_{\mathrm{F}-\mathrm{P}} 114.4\right) ; \delta_{\mathrm{P}}\left(121 \mathrm{MHz}, \mathrm{CDCl}_{3}\right) 6.30\left(\mathrm{t},{ }^{2} J_{\mathrm{P}-\mathrm{F}} 114.4\right)$ [HRMS (CI, M + 1) Found: 359.086402. Calc. for $\mathrm{C}_{16} \mathrm{H}_{18} \mathrm{~F}_{2} \mathrm{O}_{5} \mathrm{P}$ : 359.085994]; $m / z$ (LCMS, CI, $4.30 \mathrm{~min}) 376\left(30 \%, \mathrm{M}\left[\mathrm{NH}_{4}\right]^{+}\right)$, $359(100, \mathrm{M}+1), 339$ (36).

2-\{4'-[(Diethoxyphosphoryl)difluoromethyl]phenyl\}-1methylpyrrole-5-carbaldehyde 22f. As above from triflate $\mathbf{6 a}$ (1 mmol, $0.41 \mathrm{~g}$ ) and $N$-methyl-5-tributylstannylpyrrole-2carbaldehyde $21 \mathrm{f}$ ( $1 \mathrm{mmol}, 0.40 \mathrm{~g})$. Following the usual work up, purification by flash chromatography $(30 \%$ ethyl acetate in light petroleum) afforded aldehyde $\mathbf{2 2 f}$ as a brown solid which recrystallised from ether-light petroleum as light brown prisms $(0.20 \mathrm{~g}, 53 \%) ; \mathrm{mp} 71-73{ }^{\circ} \mathrm{C} ; R_{\mathrm{f}}(40 \%$ ethyl acetate in light petroleum) 0.23 (Found: $\mathrm{C}, 54.83 ; \mathrm{H}, 5.25 ; \mathrm{N}, 3.74 . \mathrm{C}_{17} \mathrm{H}_{20} \mathrm{~F}_{2}$ $\mathrm{NO}_{4} \mathrm{P}$ requires: $\left.\mathrm{C}, 54.99 ; \mathrm{H}, 5.43 ; \mathrm{N}, 3.77 \%\right) ; v_{\max }(\mathrm{KBr}) / \mathrm{cm}^{-1}$ $3470 \mathrm{~m}, 1661 \mathrm{vs}(\mathrm{C}=\mathrm{O}), 1464 \mathrm{~m}, 1279 \mathrm{~m}(\mathrm{P}=\mathrm{O}), 1116 \mathrm{~s}, 1052 \mathrm{~s}$, $1026 \mathrm{~s}, 788 \mathrm{~m}, 568 \mathrm{~m} ; \delta_{\mathrm{H}}\left(300 \mathrm{MHz}, \mathrm{CDCl}_{3}\right) 9.59(1 \mathrm{H}, \mathrm{s}, \mathrm{CHO})$, $7.70\left(2 \mathrm{H}, \mathrm{d}, J 8.1, H-3^{\prime}, H-5^{\prime}\right), 7.50\left(2 \mathrm{H}, \mathrm{d}, J 8.1, H-2^{\prime}, H-6^{\prime}\right)$, $7.0(1 \mathrm{H}, \mathrm{d}, J 4.0, H-4), 6.33(1 \mathrm{H}, \mathrm{d}, J 4.0, H-3), 4.31-4.15(4 \mathrm{H}$, $\left.\mathrm{m},-\mathrm{OCH}_{2}\right), 1.33\left(6 \mathrm{H}, \mathrm{t}, J 7.0,-\mathrm{CH}_{2} \mathrm{CH}_{3}\right) ; \delta_{\mathrm{C}}\left(75 \mathrm{MHz}, \mathrm{CDCl}_{3}\right)$ $179.8,142.8,133.6,133.4,132.7\left(\mathrm{dt},{ }^{2} J_{\mathrm{C}-\mathrm{F}} 22.0,{ }^{2} J_{\mathrm{C}-\mathrm{P}} 14.1\right)$, $129.2,126.7\left(\mathrm{t},{ }^{3} J_{\mathrm{C}-\mathrm{F}} 5.7\right), 124.4,117.9\left(\mathrm{dt},{ }^{1} J_{\mathrm{C}-\mathrm{F}} 263.4,{ }^{1} J_{\mathrm{C}-\mathrm{P}}\right.$ $218.2), 111.2,65.0\left(\mathrm{~d},{ }^{2} J_{\mathrm{C}-\mathrm{P}} 6.8\right), 34.5,16.4\left(\mathrm{~d},{ }^{3} J_{\mathrm{C}-\mathrm{P}} 5.1\right) ; \delta_{\mathrm{F}}(282$ $\left.\mathrm{MHz}, \mathrm{CDCl}_{3}\right)-108.6\left(\mathrm{~d},{ }^{2} J_{\mathrm{F}-\mathrm{P}} 114.4\right) ; \delta_{\mathrm{P}}\left(121 \mathrm{MHz}, \mathrm{CDCl}_{3}\right)$ $6.34\left(\mathrm{t},{ }^{2} J_{\mathrm{P}-\mathrm{F}}\right.$ 114.4) [HRMS (CI, M[H] ${ }^{+}$) Found: 372.117437. Calc. for $\left.\mathrm{C}_{17} \mathrm{H}_{21} \mathrm{~F}_{2} \mathrm{NO}_{4} \mathrm{P}: 372.117628\right] ; \mathrm{m} / \mathrm{z}$ (LCMS, CI, 4.41) $372\left(100 \%, \mathrm{M}\left[\mathrm{NH}_{4}\right]^{+}\right), 359(100, \mathrm{M}+1), 352$ (22), 260 (12), 232 (22)

4-(2'-Thienyl)-1-[(diethoxyphosphoryl)difluoromethyl]benzene 22g. As above from triflate 6a and 2-(tributylstannyl)thiophene 21g. Following the usual work up, purification by flash chromatography (30\% ethyl acetate in light petroleum) afforded a white solid which recrystallised from ether-light petroleum to afford $22 \mathrm{~g}(0.22 \mathrm{~g}, 64 \%)$ as white needles; $\mathrm{mp} 59-60{ }^{\circ} \mathrm{C} ; R_{\mathrm{f}}(40 \%$ ethyl acetate in light petroleum) 0.57 (Found: $\mathrm{C}, 51.97 ; \mathrm{H}, 5.15$. $\mathrm{C}_{15} \mathrm{H}_{17} \mathrm{~F}_{2} \mathrm{O}_{3} \mathrm{PS}$ requires: $\left.\mathrm{C}, 52.02 ; \mathrm{H}, 4.95 \%\right) ; v_{\max }(\mathrm{KBr}) / \mathrm{cm}^{-1}$ $1609 \mathrm{w}, 1265 \mathrm{~s}(\mathrm{P}=\mathrm{O}), 1050 \mathrm{~s}, 1014 \mathrm{vs}, 822 \mathrm{~m}, 566 \mathrm{~m} ; \delta_{\mathrm{H}}(300 \mathrm{MHz}$, $\left.\mathrm{CDCl}_{3}\right) 7.68\left(2 \mathrm{H}, \mathrm{d}, J 8.5, H-3^{\prime}, H-5^{\prime}\right), 7.61\left(2 \mathrm{H}, \mathrm{d},{ }^{3} J_{\mathrm{Ha}-\mathrm{Hb}} 8.5\right.$ $\left.\mathrm{Hz}, H-2^{\prime}, H-6^{\prime}\right), 7.37$ (1 H, d, J 3.3, H-3), 7.32 (1 H, d, J 5.2, $H-5), 7.01(1 \mathrm{H}, \mathrm{dd}, J 5.2,3.3, H-4), 4.31-4.08\left(4 \mathrm{H}, \mathrm{m},-\mathrm{OCH}_{2}\right)$, $1.32\left(6 \mathrm{H}, \mathrm{t},{ }^{3} J_{\mathrm{H}-\mathrm{H}} 7.0,-\mathrm{CH}_{2} \mathrm{CH}_{3}\right) ; \delta_{\mathrm{C}}\left(75 \mathrm{MHz}, \mathrm{CDCl}_{3}\right) 143.0$, $136.8,131.3\left(\mathrm{dt},{ }^{2} J_{\mathrm{C}-\mathrm{F}} 22.1,{ }^{2} J_{\mathrm{C}-\mathrm{P}} 14.1\right), 128.3,126.9\left(\mathrm{t},{ }^{3} J_{\mathrm{C}-\mathrm{F}} 5.1\right)$, $125.9,125.8,124.2,118.0\left(\mathrm{dt},{ }^{1} J_{\mathrm{C}-\mathrm{F}} 262.8,{ }^{1} J_{\mathrm{C}-\mathrm{P}} 219.3\right), 64.8(\mathrm{~d}$, $\left.{ }^{2} J_{\mathrm{C}-\mathrm{P}} 6.8\right), 16.4\left(\mathrm{~d},{ }^{3} J_{\mathrm{C}-\mathrm{P}} 5.7\right) ; \delta_{\mathrm{F}}\left(282 \mathrm{MHz}, \mathrm{CDCl}_{3}\right)-108.4(\mathrm{~d}$, $\left.{ }^{2} J_{\mathrm{F}-\mathrm{P}} 115.7\right) ; \delta_{\mathrm{P}}\left(121 \mathrm{MHz}, \mathrm{CDCl}_{3}\right) 6.77\left(\mathrm{t},{ }^{2} J_{\mathrm{P}-\mathrm{F}} 115.7\right)$ [HRMS $\left(\mathrm{CI}, \mathrm{M}\left[\mathrm{NH}_{4}\right]^{+}\right.$) Found: 364.095758 . Calc. for $\mathrm{C}_{15} \mathrm{H}_{21} \mathrm{~F}_{2} \mathrm{NO}_{3} \mathrm{PS}$ : 364.094785]; $\mathrm{m} / \mathrm{z}$ (CI) 347 (46\%, M + 1), 210 (100), 352 (22).

\section{4-Thiazol-2-yl-1-[(diethoxyphosphoryl)difluoromethyl]-}

benzene $22 \mathrm{~h}$. As above from triflate $6 \mathbf{a}(1 \mathrm{mmol}, 0.41 \mathrm{~g})$ and 2-(tributylstannyl)thiazole $21 \mathrm{~h}(1 \mathrm{mmol}, 0.36 \mathrm{~g})$. Following the usual work up, purification by flash chromatography (30\% ethyl acetate in light petroleum) afforded biaryl $22 \mathrm{~h}(0.18 \mathrm{~g}, 52 \%)$ as a colourless oil; $R_{\mathrm{f}}(40 \%$ ethyl acetate in light petroleum) 0.36 (Found: C, 48.50; H, 4.83; N, 3.97. $\mathrm{C}_{14} \mathrm{H}_{16} \mathrm{~F}_{2} \mathrm{NO}_{3}$ PS requires: $\mathrm{C}$, $48.41 ; \mathrm{H}, 4.64 ; \mathrm{N}, 4.03 \%) ; v_{\max }\left(\right.$ film) $/ \mathrm{cm}^{-1} 2956 \mathrm{~m}, 1480 \mathrm{w}, 1262 \mathrm{~s}$, $1021 \mathrm{~s}, 834 \mathrm{~m}, 755 \mathrm{~m} ; \delta_{\mathrm{H}}\left(300 \mathrm{MHz}, \mathrm{CDCl}_{3}\right) 8.02(2 \mathrm{H}, \mathrm{d}, J 8.1$, $\left.H-3^{\prime}, H-5^{\prime}\right), 7.86(1 \mathrm{H}, \mathrm{d}, J 3.3, H-5), 7.67\left(2 \mathrm{H}, \mathrm{d}, J 8.1, H-2^{\prime}\right.$, $\left.H-6^{\prime}\right), 7.36(1 \mathrm{H}, \mathrm{d}, J 3.3, H-4), 4.28-4.05\left(4 \mathrm{H}, \mathrm{m},-\mathrm{OCH}_{2}\right), 1.29$ $\left(6 \mathrm{H}, \mathrm{t}, J\right.$ 7.0, $\left.\mathrm{CH}_{2} \mathrm{CH}_{3}\right) ; \delta_{\mathrm{C}}\left(75 \mathrm{MHz}, \mathrm{CDCl}_{3}\right)$ 167.8, 144.1, $135.7,134.1\left(\mathrm{dt},{ }^{2} J_{\mathrm{C}-\mathrm{F}} 22.1,{ }^{2} J_{\mathrm{C}-\mathrm{P}} 13.6\right), 127.0\left(\mathrm{t},{ }^{3} J_{\mathrm{C}-\mathrm{F}} 5.1\right), 126.5$, $119.8,117.8\left(\mathrm{dt},{ }^{1} J_{\mathrm{C}-\mathrm{F}} 263.9,{ }^{1} J_{\mathrm{C}-\mathrm{P}} 218.1\right), 64.9\left(\mathrm{~d},{ }^{2} J_{\mathrm{C}-\mathrm{P}} 6.8\right), 16.4$ $\left(\mathrm{d},{ }^{3} J_{\mathrm{C}-\mathrm{P}} 5.7\right) ; \delta_{\mathrm{F}}\left(282 \mathrm{MHz}, \mathrm{CDCl}_{3}\right)-108.4\left(\mathrm{~d},{ }^{2} J_{\mathrm{F}-\mathrm{P}} 115.7\right)$; $\delta_{\mathrm{P}}\left(121 \mathrm{MHz}, \mathrm{CDCl}_{3}\right) 6.36\left(\mathrm{t},{ }^{2} J_{\mathrm{P}-\mathrm{F}} 115.7\right)$ [HRMS (CI, M + 1) Found: 348.063507. Calc. for $\left.\mathrm{C}_{14} \mathrm{H}_{17} \mathrm{~F}_{2} \mathrm{NO}_{3} \mathrm{PS}: 348.063485\right]$; $\mathrm{m} / \mathrm{z}$ (LCMS, CI, $4.37 \mathrm{~min}) 348$ (100\%, M + 1), 320 (6), 188 (11).

\section{Benzyl 5-[(diethoxyphosphoryl)difluoromethyl]-2-(2'-furyl)- benzoate 25}

A solution of triflate $13(0.546 \mathrm{~g}, 1 \mathrm{mmol}), 2$ 2-(tributylstannyl)furan $21 d(0.357 \mathrm{~g}, 1 \mathrm{mmol}), \mathrm{Pd}_{2} \mathrm{dba}_{3} \cdot \mathrm{CHCl}_{3}(0.026 \mathrm{~g}$, $2.5 \mathrm{~mol} \%)$, copper(I) iodide $(0.019 \mathrm{~g}, 0.1 \mathrm{mmol})$ and triphenylphosphine $(0.0525 \mathrm{~g}, 0.2 \mathrm{mmol})$ in dry degassed DMF $(1 \mathrm{ml})$ was heated at $80^{\circ} \mathrm{C}$ for 6 hours. The mixture was cooled, partitioned between water $(10 \mathrm{ml})$ and ethyl ether $(10 \mathrm{ml})$ and filtered through Celite. The aqueous phase was separated and extracted with ethyl ether $(3 \times 10 \mathrm{ml})$ then the combined organic extracts were dried and concentrated in vacuo to afford a yellow oil. Column chromatography ( $40 \%$ ethyl acetate in light petroleum) afforded $25(0.324 \mathrm{~g}, 70 \%)$ as a yellow oil; $R_{\mathrm{f}}\left(40 \%\right.$ ethyl acetate in light petroleum) $0.12 ; v_{\max }(\mathrm{film}) / \mathrm{cm}^{-1}$ $2981 \mathrm{~m}, 1732 \mathrm{vs}(\mathrm{C}=\mathrm{O}), 1614 \mathrm{~m}, 1273 \mathrm{vs}(\mathrm{P}=\mathrm{O}), 1225 \mathrm{vs}, 1020 \mathrm{br} \mathrm{vs}$, $739 \mathrm{~s}, 698 \mathrm{~m} ; \delta_{\mathrm{H}}\left(300 \mathrm{MHz}, \mathrm{CDCl}_{3}\right) 7.86(1 \mathrm{H}, \mathrm{s}, H-6), 7.75-7.68$ ( $\left.2 \mathrm{H}, \mathrm{m}, H-5^{\prime}, H-4\right), 7.34-7.33\left(6 \mathrm{H}, \mathrm{m}, H-3, \mathrm{CH}_{2} \mathrm{Ph}\right), 6.61(1 \mathrm{H}$, d, $\left.J 3.3, H-3^{\prime}\right), 6.42\left(1 \mathrm{H}, \mathrm{dd}, J 3.3,1.7, H-4^{\prime}\right), 5.31(2 \mathrm{H}, \mathrm{s}$, $\left.-\mathrm{OCH}_{2} \mathrm{Ph}\right), 4.27-4.15\left(4 \mathrm{H}, \mathrm{m},-\mathrm{OCH}_{2} \mathrm{CH}_{3}\right), 1.33-1.28(6 \mathrm{H}, \mathrm{m}$, $\left.-\mathrm{OCH}_{2} \mathrm{CH}_{3}\right) ; \delta_{\mathrm{C}}\left(75 \mathrm{MHz}, \mathrm{CDCl}_{3}\right) 168.1,151.2,143.4,135.3$, $131.9,131.8\left(\mathrm{td},{ }^{2} J_{\mathrm{C}-\mathrm{F}} 22.6,{ }^{2} J_{\mathrm{C}-\mathrm{P}} 14.1\right), 131.8,128.7\left(\mathrm{td},{ }^{3} J_{\mathrm{C}-\mathrm{F}} 6.8\right.$, $\left.{ }^{3} J_{\mathrm{C}-\mathrm{P}} 2.3\right), 128.7,128.6,128.4,127.9,127.2\left(\mathrm{td},{ }^{3} J_{\mathrm{C}-\mathrm{F}} 7.4,{ }^{3} J_{\mathrm{C}-\mathrm{P}}\right.$ $2.8), 117.5\left(\mathrm{td},{ }^{1} J_{\mathrm{C}-\mathrm{F}} 263.9,{ }^{1} J_{\mathrm{C}-\mathrm{P}} 218.2\right), 111.8,109.5,67.5,65.0$ $\left(\mathrm{d},{ }^{3} J_{\mathrm{C}-\mathrm{P}} 6.8\right), 16.3\left(\mathrm{~d},{ }^{3} J_{\mathrm{C}-\mathrm{P}} 5.6\right) ; \delta_{\mathrm{F}}\left(282 \mathrm{MHz}, \mathrm{CDCl}_{3}\right)-108.9$ $\left(\mathrm{d},{ }^{2} J_{\mathrm{F}-\mathrm{P}} 114.7\right) ; \delta_{\mathrm{P}}\left(121 \mathrm{MHz}, \mathrm{CDCl}_{3}\right) 6.13$ (t, $\left.{ }^{2} J_{\mathrm{P}-\mathrm{F}} 114.7\right)$ [HRMS (ES, $\mathrm{M}+1$ ) Found: 487.1095. Calc. for $\mathrm{C}_{23} \mathrm{H}_{23} \mathrm{~F}_{2-}$ $\left.\mathrm{NaO}_{6} \mathrm{P}: 487.1098\right] ; \mathrm{m} / z$ (ES) $487\left(100 \%, \mathrm{M}[\mathrm{Na}]^{+}\right)$.

1-\{4'-[(Diethoxyphosphoryl)difluoromethyl]phenyl\}-2-(trimethylsilyl)ethyne 26

$\mathrm{PdCl}_{2}\left(\mathrm{PPh}_{3}\right)_{2}(5 \mathrm{~mol} \%, 0.02 \mathrm{~g})$ was added under an atmosphere of nitrogen to a stirred solution of triflate $6 \mathrm{a}(0.24 \mathrm{mmol}, 0.1 \mathrm{~g})$, trimethylsilylethyne $(0.34 \mathrm{~g}, 0.05 \mathrm{ml})$ and triethylamine $(0.15$ $\mathrm{ml})$ in DMF $(1 \mathrm{ml})$ and the mixture was heated to $90{ }^{\circ} \mathrm{C}$ for one 
hour. After cooling, the black suspension was diluted with ethyl acetate $(10 \mathrm{ml})$ and filtered through a pad of Harbolite ${ }^{\circledR}$. The mixture was washed with brine $(2 \mathrm{ml})$, dried $\left(\mathrm{MgSO}_{4}\right)$, and concentrated in vacuo to leave a yellow oil $(0.12 \mathrm{~g})$ which was purified by column chromatography $(20 \%$ ethyl acetate in isohexane) to afford alkyne $26(0.07 \mathrm{~g}, 81 \%)$ as a pale yellow oil; $R_{r}$ $\left(20 \%\right.$ ethyl acetate in isohexane) $0.20 ; \delta_{\mathrm{H}}\left(300 \mathrm{MHz}, \mathrm{CDCl}_{3}\right)$ 7.58-7.48 (4 H, m, Ar-H), 4.28-4.0 (4 H, m, -OCH $), 1.29(6 \mathrm{H}$, $\left.\mathrm{t}, J 7.0,-\mathrm{CH}_{2} \mathrm{CH}_{3}\right), 0.25\left(9 \mathrm{H}, \mathrm{s},-\mathrm{SiCH}_{3}\right) ; \delta_{\mathrm{C}}\left(75 \mathrm{MHz}, \mathrm{CDCl}_{3}\right)$ $132.5\left(\mathrm{dt},{ }^{2} J_{\mathrm{C}-\mathrm{F}} 22.0,{ }^{2} J_{\mathrm{C}-\mathrm{P}} 14.1\right), 132.0,126.3\left(\mathrm{t},{ }^{3} J_{\mathrm{C}-\mathrm{F}} 5.6\right), 126.2$, $117.9\left(\mathrm{dt},{ }^{1} J_{\mathrm{C}-\mathrm{F}} 263.4,{ }^{1} J_{\mathrm{C}-\mathrm{P}} 218.1\right), 104.0,96.7,65.0\left(\mathrm{~d},{ }^{2} J_{\mathrm{C}-\mathrm{P}} 6.8\right)$, $16.3\left(\mathrm{~d},{ }^{3} J_{\mathrm{C}-\mathrm{P}} 5.1\right), 0.0 ; \delta_{\mathrm{F}}\left(282 \mathrm{MHz}, \mathrm{CDCl}_{3}\right)-108.9\left(\mathrm{~d},{ }^{2} J_{\mathrm{F}-\mathrm{P}}\right.$ 115.7); $\delta_{\mathrm{P}}\left(121 \mathrm{MHz}, \mathrm{CDCl}_{3}\right) 6.44\left(\mathrm{t},{ }^{2} J_{\mathrm{P}-\mathrm{F}} 115.7\right)$ [HRMS $(\mathrm{CI}, \mathrm{M}+1)$ Found: 361.120399. Calc. for $\mathrm{C}_{16} \mathrm{H}_{24} \mathrm{~F}_{2} \mathrm{O}_{3} \mathrm{PSi}$ : 361.120043]; $\mathrm{m} / \mathrm{z}$ (LCMS, CI, $5.11 \mathrm{~min}) 361(50 \%, \mathrm{M}+1), 341$ (72), 313 (20), 249 (46), 201 (100).

\section{General procedure for Suzuki coupling reactions: $1-\left\{4^{\prime}-\right.$ [(diethoxyphosphoryl)difluoromethyl]phenyl\}butane 28a}

$\mathrm{PdCl}_{2}\left(\mathrm{PPh}_{3}\right)_{2}(5 \mathrm{~mol} \%)$ was added under an atmosphere of nitrogen to a stirred solution of triflate $\mathbf{6 a}(1.0 \mathrm{mmol})$, boronic acid $27 \mathrm{a}(2.0 \mathrm{mmol})$ and triethylamine $(4.0 \mathrm{mmol}, 0.56 \mathrm{ml})$ in $\operatorname{DMF}(3 \mathrm{ml})$ and the mixture was heated to $90{ }^{\circ} \mathrm{C}$ for the time indicated (consumption of the triflate as shown by TLC). After cooling, the black suspension was diluted with ethyl acetate, and washed sequentially with aqueous solutions of $\mathrm{NaHCO}_{3}$ $(3 \mathrm{ml})$, water $(3 \mathrm{ml}), 2 \mathrm{M}$ citric acid $(3 \mathrm{ml})$ and brine $(3 \mathrm{ml})$. After drying $\left(\mathrm{MgSO}_{4}\right)$, the solvent was removed in vacuo. Purification by flash chromatography $(20 \%$ ethyl acetate in isohexane) afforded $28 \mathrm{a}(0.20 \mathrm{~g}, 63 \%)$ as a colourless oil; $R_{\mathrm{f}}(20 \%$ ethyl acetate in isohexane) 0.19 (Found: $\mathrm{C}, 55.92 ; \mathrm{H}, 7.29 . \mathrm{C}_{15} \mathrm{H}_{23}$ $\mathrm{F}_{2} \mathrm{O}_{3} \mathrm{P}$ requires: C, 56.25; $\left.\mathrm{H}, 7.24 \%\right) ; v_{\max }($ film $) / \mathrm{cm}^{-1} 2932 \mathrm{w}$, $1271 \mathrm{~s}(\mathrm{P}=\mathrm{O}), 1048 \mathrm{~s}, 1019 \mathrm{~s} ; \delta_{\mathrm{H}}\left(300 \mathrm{MHz}, \mathrm{CDCl}_{3}\right) 7.49(2 \mathrm{H}, \mathrm{d}$, $J$ 7.7, $\left.H-3^{\prime}, H-5^{\prime}\right), 7.24\left(2 \mathrm{H}, \mathrm{d}, J 7.7, H-2^{\prime}, H-6^{\prime}\right), 4.27-4.0(4 \mathrm{H}$, $\left.\mathrm{m},-\mathrm{OCH}_{2}\right), 2.62\left(2 \mathrm{H}, J\right.$ 7.7, $\left.\mathrm{ArCH} 2^{-}\right), 1.65-1.52(2 \mathrm{H}, \mathrm{m}$, $\left.-\mathrm{CH}_{2} \mathrm{Et}\right), 1.37-1.21\left(8 \mathrm{H}, \mathrm{m},-\mathrm{CH}_{2} \mathrm{CH}_{2} \mathrm{CH}_{3},-\mathrm{OCH}_{2} \mathrm{CH}_{3}\right), 0.90$ $\left(3 \mathrm{H}, \mathrm{t}, J 7.2,-\mathrm{CH}_{2} \mathrm{CH}_{2} \mathrm{CH}_{3}\right) ; \delta_{\mathrm{C}}\left(75 \mathrm{MHz}, \mathrm{CDCl}_{3}\right) 145.9,129.8$ $\left(\mathrm{dt},{ }^{2} J_{\mathrm{C}-\mathrm{F}} 22.0,{ }^{2} J_{\mathrm{C}-\mathrm{P}} 13.6\right), 128.5,126.1\left(\mathrm{dt},{ }^{3} J_{\mathrm{C}-\mathrm{F}} 6.5,{ }^{3} J_{\mathrm{C}-\mathrm{P}} 2.3\right)$, $118.3\left(\mathrm{dt},{ }^{1} J_{\mathrm{C}-\mathrm{F}} 262.8,{ }^{1} J_{\mathrm{C}-\mathrm{P}} 219.3\right), 64.7\left(\mathrm{~d},{ }^{2} J_{\mathrm{C}-\mathrm{P}} 6.8\right), 35.5,33.4$, $22.3,16.3\left(\mathrm{~d},{ }^{3} J_{\mathrm{C}-\mathrm{P}} 5.7\right), 13.9 ; \delta_{\mathrm{F}}\left(282 \mathrm{MHz}, \mathrm{CDCl}_{3}\right)-107.8(\mathrm{~d}$, $\left.{ }^{2} J_{\mathrm{F}-\mathrm{P}} 118.3\right) ; \delta_{\mathrm{P}}\left(121 \mathrm{MHz}, \mathrm{CDCl}_{3}\right) 6.95\left(\mathrm{t},{ }^{2} J_{\mathrm{P}-\mathrm{F}} 118.3\right)$ [HRMS $(\mathrm{CI}, \mathrm{M}+1)$ Found: 321.142830. Calc. for $\mathrm{C}_{15} \mathrm{H}_{24} \mathrm{~F}_{2} \mathrm{O}_{3} \mathrm{P}$ : 321.143115]; $\mathrm{m} / \mathrm{z}$ (LCMS, CI, $4.93 \mathrm{~min}) 321(34 \%, \mathrm{M}+1), 301$ (33), 273 (8), 209 (21), 181 (25), 161 (100).

4-Chloro-1-\{4'-[(diethoxyphosphoryl)difluoromethyl]phenyl\}benzene $28 \mathrm{~b}$. Aryl triflate $\mathbf{6 a}$ and 4-chlorophenylboronic acid were treated as described above for 80 minutes. Following the usual work up, purification by flash chromatography (30\% ethyl acetate in isohexane) afforded the biaryl chloride $\mathbf{2 8 b}(0.27 \mathrm{~g}$, $72 \%)$ as a pale yellow oil; $R_{\mathrm{f}}(40 \%$ ethyl acetate in isohexane) 0.39 (Found: $\mathrm{C}, 54.67 ; \mathrm{H}, 5.00 . \mathrm{C}_{17} \mathrm{H}_{18} \mathrm{ClF}_{2} \mathrm{O}_{3} \mathrm{P}$ requires: $\mathrm{C}$, $54.49 ; \mathrm{H}, 4.84 \%) ; v_{\max }\left(\right.$ film) $/ \mathrm{cm}^{-1} 2985 \mathrm{w}, 1613 \mathrm{w}, 1487 \mathrm{~m}, 1260 \mathrm{~s}$ $(\mathrm{P}=\mathrm{O}), 1018 \mathrm{~s}, 817 \mathrm{~s} ; \delta_{\mathrm{H}}\left(300 \mathrm{MHz}, \mathrm{CDCl}_{3}\right) 7.68(2 \mathrm{H}, \mathrm{d}, J 8.5$, $\left.H-3^{\prime}, H-5^{\prime}\right), 7.62\left(2 \mathrm{H}, \mathrm{d}, J 8.5, H-2^{\prime}, H-6^{\prime}\right), 7.52(2 \mathrm{H}, \mathrm{d}, J 8.5$, $H-3, H-5), 7.42(2 \mathrm{H}, \mathrm{d}, J 8.5, H-2, H-6), 4.32-4.10(4 \mathrm{H}, \mathrm{m}$, $\left.-\mathrm{OCH}_{2}\right), 1.33\left(6 \mathrm{H}, \mathrm{t}, J \mathrm{~T} .0,-\mathrm{CH}_{2} \mathrm{CH}_{3}\right) ; \delta_{\mathrm{C}}\left(75 \mathrm{MHz}, \mathrm{CDCl}_{3}\right)$ $142.7,138.2,134.2,131.7\left(\mathrm{dt},{ }^{2} J_{\mathrm{C}-\mathrm{F}} 22.0,{ }^{2} J_{\mathrm{C}-\mathrm{P}} 13.6\right), 129.1$, $128.5,127.0,126.9\left(\mathrm{t},{ }^{3} J_{\mathrm{C}-\mathrm{F}} 6.2\right), 118.1\left(\mathrm{dt},{ }^{1} J_{\mathrm{C}-\mathrm{F}} 263.4,{ }^{1} J_{\mathrm{C}-\mathrm{P}}\right.$ $218.7), 64.9\left(\mathrm{~d},{ }^{2} J_{\mathrm{C}-\mathrm{P}} 6.8\right), 16.4\left(\mathrm{~d},{ }^{3} J_{\mathrm{C}-\mathrm{P}} 5.7\right) ; \delta_{\mathrm{F}}(282 \mathrm{MHz}$, $\left.\mathrm{CDCl}_{3}\right)-108.3\left(\mathrm{~d},{ }^{2} J_{\mathrm{F}-\mathrm{P}} 115.7\right) ; \delta_{\mathrm{P}}\left(121 \mathrm{MHz}, \mathrm{CDCl}_{3}\right) 6.62(\mathrm{t}$, ${ }^{2} J_{\text {P-F }} 115.7$ ); [HRMS (CI, M + 1) Found: 375.072243. Calc. for $\mathrm{C}_{17} \mathrm{H}_{19} \mathrm{ClF}_{2} \mathrm{O}_{3} \mathrm{P}: 375.072842$ ]; $\mathrm{m} / \mathrm{z}$ (LCMS, CI, $4.98 \mathrm{~min}$ ) 394 $\left(9 \%,{ }^{37} \mathrm{M}\left[\mathrm{NH}_{4}\right]^{+}\right), 392\left(29 \%,{ }^{35} \mathrm{M}\left[\mathrm{NH}_{4}\right]^{+}\right), 377\left(29,{ }^{37} \mathrm{M}+1\right)$, $375\left(100,{ }^{35} \mathrm{M}+1\right), 355(34)$.

4-Bromo-1-\{4'-[(diethoxyphosphoryl)difluoromethyl]phenyl $\}$ benzene 28c. Aryl triflate 6a and 4-bromophenylboronic acid were treated as described above for 80 minutes. Following the usual work up, purification by flash chromatography ( $40 \%$ ether in isohexane) afforded biaryl 28c $(0.20 \mathrm{~g}, 48 \%)$ as a pale yellow oil; $R_{\mathrm{f}}\left(40 \%\right.$ ethyl acetate in isohexane) $0.20 ; v_{\max }(\mathrm{film}) / \mathrm{cm}^{-1}$ $2933 \mathrm{~m}, 1613 \mathrm{~m}, 1588 \mathrm{~m}, 1483 \mathrm{~s}, 1390 \mathrm{~m}, 1260 \mathrm{~s}(\mathrm{P}=\mathrm{O}), 1020 \mathrm{br}$ s, $813 \mathrm{~s} ; \delta_{\mathrm{H}}\left(300 \mathrm{MHz}, \mathrm{CDCl}_{3}\right) 7.68\left(2 \mathrm{H}, \mathrm{d}, J 8.1, H-3^{\prime}, H-5^{\prime}\right), 7.62$ $\left(2 \mathrm{H}, \mathrm{d}, J 8.1, H-4^{\prime}, H-6^{\prime}\right), 7.58(2 \mathrm{H}, \mathrm{d}, J 8.5, H-3, H-5), 7.45$ ( $\left.2 \mathrm{H}, \mathrm{d}, J 8.5, H-4^{\prime}, H-6^{\prime}\right), 4.33-4.11\left(4 \mathrm{H}, \mathrm{m},-\mathrm{OCH}_{2}\right), 1.33(6 \mathrm{H}$, t, $J$ 7.0, $\left.-\mathrm{CH}_{2} \mathrm{CH}_{3}\right) ; \delta_{\mathrm{C}}\left(75 \mathrm{MHz}, \mathrm{CDCl}_{3}\right) 142.4,138.9,132.1$, $131.7\left(\mathrm{dt},{ }^{2} J_{\mathrm{C}-\mathrm{F}} 22.0,{ }^{2} J_{\mathrm{C}-\mathrm{P}} 13.6\right), 128.9,127.0,126.9\left(\mathrm{t},{ }^{3} J_{\mathrm{C}-\mathrm{F}} 6.2\right)$, $122.4,118.5\left(\mathrm{dt},{ }^{1} J_{\mathrm{C}-\mathrm{F}} 263.9,{ }^{1} J_{\mathrm{C}-\mathrm{P}} 218.5\right), 64.9\left(\mathrm{~d},{ }^{2} J_{\mathrm{C}-\mathrm{P}} 6.8\right), 16.4$ $\left(\mathrm{d},{ }^{3} J_{\mathrm{C}-\mathrm{P}} 5.1\right) ; \delta_{\mathrm{F}}\left(282 \mathrm{MHz}, \mathrm{CDCl}_{3}\right)-108.4\left(\mathrm{~d},{ }^{2} J_{\mathrm{F}-\mathrm{P}} 116.4\right)$; $\delta_{\mathrm{P}}\left(121 \mathrm{MHz}, \mathrm{CDCl}_{3}\right) 6.60\left(\mathrm{t},{ }^{2} J_{\mathrm{P}-\mathrm{F}} 116.4\right)$ [HRMS (CI, M + 1) Found: 419.0223. Calc. for $\mathrm{C}_{17} \mathrm{H}_{19} \mathrm{BrF}_{2} \mathrm{O}_{3} \mathrm{P}$ : 419.0209]; $\mathrm{m} / \mathrm{z}$ (CI) $438\left(100 \%,{ }^{81} \mathrm{M}\left[\mathrm{NH}_{4}\right]^{+}\right), 436\left(100,{ }^{79} \mathrm{M}\left[\mathrm{NH}_{4}\right]^{+}\right), 421$ (31, $\left.{ }^{81} \mathrm{M}+1\right), 420\left(17,{ }^{81} \mathrm{M}\right), 419\left(31,{ }^{79} \mathrm{M}+1\right), 418\left(12,{ }^{79} \mathrm{M}\right)$, 358 (14).

\section{$2-\left\{4^{\prime}-[(\right.$ Diethoxyphosphoryl)difluoromethyl]phenyl $\}$ benzalde-} hyde 28d. Aryl triflate 6a and 2-formylphenylboronic acid were treated as described above for 1 hour. Following the usual work up, purification by flash chromatography ( $20 \%$ ethyl acetate in isohexane) afforded biaryl $28 d(0.23 \mathrm{~g}, 63 \%)$ as a yellow oil; $R_{\mathrm{f}}$ ( $40 \%$ ethyl acetate in isohexane) 0.13 (Found: C, 58.68; H, 4.99. $\mathrm{C}_{18} \mathrm{H}_{19} \mathrm{~F}_{2} \mathrm{O}_{4} \mathrm{P}$ requires: $\mathrm{C}, 58.70 ; \mathrm{H}, 5.20 \%$ ); $\delta_{\mathrm{H}}\left(300 \mathrm{MHz}, \mathrm{CDCl}_{3}\right) 9.91(1 \mathrm{H}, \mathrm{s}, C H O), 7.98(1 \mathrm{H}, \mathrm{d}, J$ 7.4, $H-3), 7.69\left(2 \mathrm{H}, \mathrm{d}, J 7.7, H-3^{\prime}, H-5^{\prime}\right), 7.66-7.58(1 \mathrm{H}, \mathrm{m}, H-5)$, 7.53-7.36 (4 H, m, H-4, H-6,H-2',H-6'), 4.31-4.10 (4 H, m, $\left.-\mathrm{OCH}_{2}\right), 1.30\left(6 \mathrm{H}, \mathrm{t}, J 7.0,-\mathrm{CH}_{2} \mathrm{CH}_{3}\right) ; \delta_{\mathrm{C}}\left(75 \mathrm{MHz}, \mathrm{CDCl}_{3}\right)$ $191.8,144.6,140.4,133.7,133.6,132.5\left(\mathrm{dt},{ }^{2} J_{\mathrm{C}-\mathrm{F}} 22.0,{ }^{2} J_{\mathrm{C}-\mathrm{P}}\right.$ $14.1), 130.7,130.1,128.4,127.9,126.4\left(\mathrm{t},{ }^{3} J_{\mathrm{C}-\mathrm{F}} 5.1\right), 118.0(\mathrm{dt}$, $\left.{ }^{1} J_{\mathrm{C}-\mathrm{F}} 263.4,{ }^{1} J_{\mathrm{C}-\mathrm{P}} 218.7\right), 64.0\left(\mathrm{~d},{ }^{2} J_{\mathrm{C}-\mathrm{P}} 6.8\right), 16.4\left(\mathrm{~d},{ }^{3} J_{\mathrm{C}-\mathrm{P}} 5.1\right)$; $\delta_{\mathrm{F}}\left(282 \mathrm{MHz}, \mathrm{CDCl}_{3}\right)-108.4\left(\mathrm{~d},{ }^{2} J_{\mathrm{F}-\mathrm{P}} 115.7\right) ; \delta_{\mathrm{P}}(121 \mathrm{MHz}$, $\left.\mathrm{CDCl}_{3}\right) 6.40\left(\mathrm{t},{ }^{2} J_{\mathrm{P}-\mathrm{F}}\right.$ 115.7) [HRMS (CI, M + 1) Found: 369.107004. Calc. for $\mathrm{C}_{18} \mathrm{H}_{20} \mathrm{~F}_{2} \mathrm{O}_{4} \mathrm{P}: 369.106729$ ]; $\mathrm{m} / \mathrm{z}$ (LCMS, CI, $4.55 \mathrm{~min}) 386\left(8 \%, \mathrm{M}\left[\mathrm{NH}_{4}\right]^{+}\right), 369(100, \mathrm{M}+1), 341(19)$.

1-\{4'-[(Diethoxyphosphoryl)difluoromethyl]phenyl\}-3-nitrobenzene 28e. Aryl triflate 6a and 3-nitrophenylboronic acid were treated as described above for 1 hour. Following the usual work up, purification by flash chromatography $(30 \%$ ethyl acetate in isohexane) afforded an off white solid which crystallised from ether-isohexane to yield biaryl 28e $(0.33 \mathrm{~g}, 86 \%)$ as white needles, $\mathrm{mp} 65-67^{\circ} \mathrm{C} ; R_{\mathrm{f}}(40 \%$ ethyl acetate in isohexane) 0.23 (Found: $\mathrm{C}, 53.07 ; \mathrm{H}, 4.51 ; \mathrm{N}, 3.59 . \mathrm{C}_{17} \mathrm{H}_{18} \mathrm{~F}_{2} \mathrm{NO}_{5} \mathrm{P}$ requires: $\mathrm{C}$, $52.99 ; \mathrm{H}, 4.71 ; \mathrm{N}, 3.64 \%) ; \delta_{\mathrm{H}}\left(300 \mathrm{MHz}, \mathrm{CDCl}_{3}\right) 8.42(1 \mathrm{H}, \mathrm{s}$, $H-2), 8.20(1 \mathrm{H}, \mathrm{d}, J 8.1, H-4), 7.90(1 \mathrm{H}, \mathrm{d}, J 7.7, H-6), 7.72(2 \mathrm{H}$, d, $\left.J 8.8, H-3^{\prime}, H-5^{\prime}\right), 7.68\left(2 \mathrm{H}, \mathrm{d}, J 8.8, H-4^{\prime}, H-6^{\prime}\right), 7.61(1 \mathrm{H}$, dd, $J 8.1,7.7, H-5), 4.32-4.10\left(4 \mathrm{H}, \mathrm{m},-\mathrm{OCH}_{2}\right), 1.33(6 \mathrm{H}, \mathrm{t}$, $J$ 7.0, $\left.-\mathrm{CH}_{2} \mathrm{CH}_{3}\right) ; \delta_{\mathrm{C}}\left(75 \mathrm{MHz}, \mathrm{CDCl}_{3}\right) 148.8,141.7,141.1$, $133.2,132.8\left(\mathrm{dt},{ }^{2} J_{\mathrm{C}-\mathrm{F}} 22.0,{ }^{2} J_{\mathrm{C}-\mathrm{P}} 14.1\right), 130.0,127.3,127.2$, $122.7,122.1,118.0\left(\mathrm{dt},{ }^{1} J_{\mathrm{C}-\mathrm{F}} 263.4,{ }^{1} J_{\mathrm{C}-\mathrm{P}} 218.2\right), 64.9\left(\mathrm{~d},{ }^{2} J_{\mathrm{C}-\mathrm{P}}\right.$ $6.8), 16.2\left(\mathrm{~d},{ }^{3} J_{\mathrm{C}-\mathrm{P}} 5.1\right) ; \delta_{\mathrm{F}}\left(282 \mathrm{MHz}, \mathrm{CDCl}_{3}\right)-108.5\left(\mathrm{~d},{ }^{2} J_{\mathrm{F}-\mathrm{P}}\right.$ 115.7); $\delta_{\mathrm{P}}\left(121 \mathrm{MHz}, \mathrm{CDCl}_{3}\right) 6.41\left(\mathrm{t},{ }^{2} J_{\mathrm{P}-\mathrm{F}} 115.7\right)$ [HRMS $\left(\mathrm{CI}, \mathrm{M}+1\right.$ ) Found: 386.096478. Calc. for $\mathrm{C}_{17} \mathrm{H}_{19} \mathrm{~F}_{2} \mathrm{NO}_{5} \mathrm{P}$ : 386.096893]; $\mathrm{m} / \mathrm{z}$ (LCMS, CI, $4.72 \mathrm{~min}) 403\left(59 \%, \mathrm{M}\left[\mathrm{NH}_{4}\right]^{+}\right)$, $386(100, \mathrm{M}+1), 366(10), 274(9)$.

\section{1-\{4'-[(Diethoxyphosphoryl)difluoromethyl]phenyl $\}-3,4$}

dimethoxybenzene 28f. Aryl triflate 6a and 3,4-dimethoxyphenylboronic acid were treated as described above for 2 hours. Following the usual work up, purification by flash chromatography ( $80 \%$ ether in isohexane) afforded the biaryl $28 f(0.18 \mathrm{~g}, 45 \%)$ as a pale yellow semi-solid; $R_{\mathrm{f}}(40 \%$ ethyl acetate in isohexane) 0.29 (Found: $\mathrm{C}, 57.05 ; \mathrm{H}, 5.75$. $\mathrm{C}_{19} \mathrm{H}_{23} \mathrm{~F}_{2} \mathrm{O}_{5} \mathrm{P}$ requires: $\left.\mathrm{C}, 57.00 ; \mathrm{H}, 5.79 \%\right) ; v_{\max }(\mathrm{KBr}) / \mathrm{cm}^{-1}$ $1611 \mathrm{~m}, 1526 \mathrm{~m}, 1504 \mathrm{~m}, 1266 \mathrm{~s}(\mathrm{P}=\mathrm{O}), 1029 \mathrm{~s}, 805 \mathrm{~m}, 576 \mathrm{~m}$; $\delta_{\mathrm{H}}\left(300 \mathrm{MHz}, \mathrm{CDCl}_{3}\right) 7.66\left(2 \mathrm{H}, \mathrm{d}, J 9.4, H-3^{\prime}, H-5^{\prime}\right), 7.62(2 \mathrm{H}$, d, $\left.J 9.4, H-4^{\prime}, H-6^{\prime}\right), 7.16(1 \mathrm{H}, \mathrm{dd}, J 8.5,1.2, H-6), 7.10(1 \mathrm{H}, \mathrm{d}$, $J 1.2, H-2), 6.95(1 \mathrm{H}, \mathrm{d}, J 8.5, H-5), 4.29-4.10\left(4 \mathrm{H}, \mathrm{m},-\mathrm{OCH}_{2}\right)$, $3.94\left(3 \mathrm{H}, \mathrm{s},-\mathrm{OCH}_{3}\right), 3.92\left(3 \mathrm{H}, \mathrm{s},-\mathrm{OCH}_{3}\right), 1.33(6 \mathrm{H}, \mathrm{t}, J 7.0 \mathrm{~Hz}$, 
$\left.-\mathrm{CH}_{2} \mathrm{CH}_{3}\right) ; \delta_{\mathrm{C}}\left(75 \mathrm{MHz}, \mathrm{CDCl}_{3}\right)$ 149.1, 149.0, 143.3, 132.7, $130.6\left(\mathrm{dt},{ }^{2} J_{\mathrm{C}-\mathrm{F}} 22.0,{ }^{2} J_{\mathrm{C}-\mathrm{P}} 13.6\right), 126.6,126.5\left(\mathrm{t},{ }^{3} J_{\mathrm{C}-\mathrm{F}} 6.2\right), 119.4$, $118.0\left(\mathrm{dt},{ }^{1} J_{\mathrm{C}-\mathrm{F}} 263.4,{ }^{1} J_{\mathrm{C}-\mathrm{P}} 219.3\right), 111.3,110.1,64.6\left(\mathrm{~d},{ }^{2} J_{\mathrm{C}-\mathrm{P}}\right.$ 6.8), 55.8, $16.2\left(\mathrm{~d},{ }^{3} J_{\mathrm{C}-\mathrm{P}} 5.7\right) ; \delta_{\mathrm{F}}\left(282 \mathrm{MHz}, \mathrm{CDCl}_{3}\right)-108.2(\mathrm{~d}$, $\left.{ }^{2} J_{\text {F-P }} 116.9\right) ; \delta_{\mathrm{P}}\left(121 \mathrm{MHz}, \mathrm{CDCl}_{3}\right) 6.77\left(\mathrm{t},{ }^{2} J_{\mathrm{P}-\mathrm{F}} 116.9\right)$ [HRMS $(\mathrm{CI}, \mathrm{M}+1)$ Found: 401.132944. Calc. for $\mathrm{C}_{19} \mathrm{H}_{24} \mathrm{~F}_{2} \mathrm{O}_{5} \mathrm{P}$ : 401.132944]; $\mathrm{m} / \mathrm{z}$ (LCMS, CI, $4.53 \mathrm{~min}) 418\left(100 \%, \mathrm{M}\left[\mathrm{NH}_{4}\right]^{+}\right)$, $401(67, M+1), 381(54)$.

4-(3'-Thienyl)-1-[(diethoxyphosphoryl)difluoromethyl]benzene 28g. Aryl triflate 6a and 3 -thienyl boronic acid were treated as described above for 80 minutes. Following the usual work up, purification by flash chromatography $(30 \%$ ethyl acetate in isohexane) afforded a light brown solid which crystallised from ether-isohexane to yield biaryl $\mathbf{2 8 g}(0.26 \mathrm{~g}, 75 \%)$ as off-white prisms, $\mathrm{mp} 60-62{ }^{\circ} \mathrm{C} ; R_{\mathrm{f}}(40 \%$ ethyl acetate in isohexane) 0.39 (Found: $\mathrm{C}, 52.12 ; \mathrm{H}, 4.79 . \mathrm{C}_{15} \mathrm{H}_{17} \mathrm{~F}_{2} \mathrm{O}_{3} \mathrm{PS}$ requires: $\mathrm{C}, 52.02 ; \mathrm{H}$, $4.95 \%) ; v_{\max }(\mathrm{KBr}) / \mathrm{cm}^{-1} 1611 \mathrm{w}, 1265 \mathrm{~s}(\mathrm{P}=\mathrm{O}), 1014 \mathrm{~s}, 786 \mathrm{~s}, 567 \mathrm{~s}$; $\delta_{\mathrm{H}}\left(300 \mathrm{MHz}, \mathrm{CDCl}_{3}\right) 7.67(2 \mathrm{H}, \mathrm{d}, J 8.8, H-3, H-5), 7.63(2 \mathrm{H}, \mathrm{d}$, $J$ 8.8, H-2, H-6), 7.54-7.50 (1 H, m, H-4'), 7.43-7.39 (2 H, m, $\left.H-2^{\prime}, H-5^{\prime}\right), 4.30-4.09\left(4 \mathrm{H}, \mathrm{m},-\mathrm{OCH}_{2}\right), 1.32(6 \mathrm{H}, \mathrm{t}, J 7.0$, $\left.-\mathrm{CH}_{2} \mathrm{CH}_{3}\right) ; \delta_{\mathrm{C}}\left(75 \mathrm{MHz}, \mathrm{CDCl}_{3}\right) 141.2,138.2,131.1\left(\mathrm{dt},{ }^{2} J_{\mathrm{C}-\mathrm{F}}\right.$ $\left.22.0,{ }^{2} J_{\mathrm{C}-\mathrm{P}} 13.6\right), 126.8\left(\mathrm{t},{ }^{3} J_{\mathrm{C}-\mathrm{F}} 6.2\right), 126.7,126.4,126.2,121.5$, $118.1\left(\mathrm{dt},{ }^{1} J_{\mathrm{C}-\mathrm{F}} 262.8,{ }^{1} J_{\mathrm{C}-\mathrm{P}} 219.3\right), 64.9\left(\mathrm{~d},{ }^{2} J_{\mathrm{C}-\mathrm{P}} 6.2\right), 16.4(\mathrm{~d}$, $\left.{ }^{3} J_{\mathrm{C}-\mathrm{P}} 5.7\right) ; \delta_{\mathrm{F}}\left(282 \mathrm{MHz}, \mathrm{CDCl}_{3}\right)-108.3\left(\mathrm{~d},{ }^{2} J_{\mathrm{F}-\mathrm{P}} 117.0\right) ; \delta_{\mathrm{P}}(121$ $\left.\mathrm{MHz}, \mathrm{CDCl}_{3}\right) 6.74\left(\mathrm{t},{ }^{2} J_{\mathrm{P}-\mathrm{F}} 117.0\right)$ [HRMS (CI, M + 1) Found: 347.067978. Calc. for $\mathrm{C}_{15} \mathrm{H}_{18} \mathrm{~F}_{2} \mathrm{O}_{3} \mathrm{PS}: 347.068236$ ]; $\mathrm{m} / \mathrm{z}$ (LCMS, CI, $4.69 \mathrm{~min}) 364\left(13 \%, \mathrm{M}\left[\mathrm{NH}_{4}\right]^{+}\right), 347(72, \mathrm{M}+1), 327$ (97), 299 (12), 235 (59), 187 (100).

4-(1-Benzofuran-2-yl)-1-[(diethoxyphosphoryl)difluoromethyl]benzene $28 \mathrm{~h}$. Aryl triflate $\mathbf{6 a}$ and 1-benzofuran-2-ylboronic acid were treated as described above for 1 hour. Following the usual work up, purification by flash chromatography $(20 \%$ ethyl acetate in isohexane) afforded an off white solid which crystallised from ether-isohexane to afford biaryl $\mathbf{2 8 h}(0.25 \mathrm{~g}, 66 \%)$ as white plates, $\mathrm{mp} 104-106^{\circ} \mathrm{C} ; R_{\mathrm{f}}(40 \%$ ethyl acetate in isohexane) 0.33 (Found: C, 59.72; H, 4.88. $\mathrm{C}_{19} \mathrm{H}_{19} \mathrm{~F}_{2} \mathrm{O}_{4} \mathrm{P}$ requires: $\mathrm{C}, 60.00 ; \mathrm{H}$, $5.04 \%) ; v_{\max }(\mathrm{KBr}) / \mathrm{cm}^{-1} 1269 \mathrm{~s}, 1014 \mathrm{~s}, 809 \mathrm{~m}, 753 \mathrm{~m} ; \delta_{\mathrm{H}}(300$ $\left.\mathrm{MHz}, \mathrm{CDCl}_{3}\right) 7.93(2 \mathrm{H}, \mathrm{d}, J$ 8.1, $H-3, H-5), 7.69(2 \mathrm{H}, \mathrm{d}, J$ 8.1, $H-2, H-6), 7.59\left(1 \mathrm{H}, \mathrm{d}, J 7.0, H-7^{\prime}\right), 7.53\left(1 \mathrm{H}, \mathrm{d}, J 8.1, H-4^{\prime}\right)$, 7.53-7.20 (2 H, m, H-4' $\left.H-6^{\prime}\right), 7.10\left(1 \mathrm{H}, \mathrm{s}, H-3^{\prime}\right), 4.31-4.10$ $(4 \mathrm{H}, \mathrm{m},-\mathrm{OCH}), 1.32\left(6 \mathrm{H}, \mathrm{t},{ }^{3} \mathrm{~J}_{\mathrm{H}-\mathrm{H}} 7.0,-\mathrm{CH}_{2} \mathrm{CH}_{3}\right) ; \delta_{\mathrm{C}}(75 \mathrm{MHz}$, $\left.\mathrm{CDCl}_{3}\right) 155.1,154.6,132.8,132.3\left(\mathrm{dt},{ }^{2} J_{\mathrm{C}-\mathrm{F}} 22.0,{ }^{2} J_{\mathrm{C}-\mathrm{P}} 13.6\right)$, $129.0,126.8\left(\mathrm{t},{ }^{3} J_{\mathrm{C}-\mathrm{F}} 5.6\right), 124.9,124.8,123.2,121.3,118.0(\mathrm{dt}$, $\left.{ }^{1} J_{\mathrm{C}-\mathrm{F}} 262.8,{ }^{1} J_{\mathrm{C}-\mathrm{P}} 218.7\right), 111.3,102.9,64.9\left(\mathrm{~d},{ }^{2} J_{\mathrm{C}-\mathrm{P}} 6.8\right), 16.4(\mathrm{~d}$, $\left.{ }^{3} J_{\mathrm{C}-\mathrm{P}} 5.1\right) ; \delta_{\mathrm{F}}\left(282 \mathrm{MHz}, \mathrm{CDCl}_{3}\right)-108.5\left(\mathrm{~d},{ }^{2} J_{\mathrm{F}-\mathrm{P}} 115.4\right) ; \delta_{\mathrm{P}}(121$ $\left.\mathrm{MHz}, \mathrm{CDCl}_{3}\right) 6.60\left(\mathrm{t},{ }^{2} J_{\mathrm{P}-\mathrm{F}} 115.4\right)$ [HRMS (CI, M + 1) Found: 381.106867. Calc. for $\left.\mathrm{C}_{19} \mathrm{H}_{20} \mathrm{~F}_{2} \mathrm{O}_{4} \mathrm{P}: 381.106729\right]$; $m / z$ (LCMS, CI, $5.00 \mathrm{~min}) 398\left(50 \%, \mathrm{M}\left[\mathrm{NH}_{4}\right]^{+}\right), 381(100, \mathrm{M}+1), 361(43)$.

\section{Acknowledgements}

The authors wish to thank the EU (ERASMUS studentship to S. P.), EPSRC (Quota CASE studentship to H. J. E.) and GlaxoWellcome for financial support and Professor T. Yokomatsu of Tokyo University, Japan for helpful discussions.

\section{References}

1 T. R. Burke and Z. Y. Zhang, Biopolymers, 1998, 47, 225. 2 T. K. Sawyer, Biopolymers, 1998, 47, 243.

3 C. García-Echeverría, P. Furet, B. Gay, H. Fretz, J. Rahuel, J. Schoepfer and G. Caravatti, J. Med. Chem., 1998, 41, 1741.

4 J. Schoepfer, B. Gay, G. Caravatti, C. Garcia-Echeverria, H. Fretz, J. Rahuel and P. Furet, Bioorg. Med. Chem. Lett., 1998, 8, 2865.
5 J. Schoepfer, H. Fretz, B. Gay, P. Furet, C. Garcia-Echeverria, N. End and G. Caravatti, Bioorg. Med. Chem. Lett., 1999, 9, 221.

6 P. L. Beaulieu, D. R. Cameron, J. M. Ferland, J. Gauthier, E. Ghiro, J. Gillard, V. Gorys, M. Poirier, J. Rancourt, D. Wernic, M. LlinasBrunet, R. Betageri, M. Cardozo, E. R. Hickey, R. Ingraham, S. Jakes, A. Kabcenell, T. Kirrane, S. Lukas, U. Patel, J. Proudfoot, R. Sharma, L. Tong and N. Moss, J. Med. Chem., 1999, 42, 1757.

7 P. J. Hajduk, M.-M. Zhou and S. W. Fesik, Bioorg. Med. Chem. Lett., 9, 2403.

8 E. A. Lunney, K. S. Para, J. R. Rubin, C. Humblet, J. H. Fergus, J. S. Marks and T. K. Sawyer, J. Am. Chem. Soc., 1997, 119, 12471.

9 G. J. Pacofsky, K. Lackey, K. J. Alligood, J. Berman, P. S. Charifson, R. M. Crosby, G. F. Dorsey, P. L. Feldman, T. M. Gilmer, C. W. Hummel, S. R. Jordan, C. Mohr, L. M. Shewchuk, D. D. Sternbach and M. Rodriguez, J. Med. Chem., 1998, 41, 1894.

10 P. S. Charifson, L. M. Shewchuk, W. Rocque, C. W. Hummel, S. R. Jordan, C. Mohr, G. J. Pacofsky, M. R. Peel, M. Rodriguez, D. D. Sternbach and T. G. Consler, Biochemistry, 1997, 36, 6283.

11 J. L. Buchanan, C. B. Vu, T. J. Merry, E. G. Corpuz, S. G. Pradeepan, U. N. Mani, M. Yang, H. R. Plake, V. M. Varkhedkar, B. A. Lynch, I. A. MacNeil, K. A. Loiacono, C. L. Tiong and D. A. Holt, Bioorg. Med. Chem. Lett., 1999, 9, 2359.

12 J. L. Buchanan, R. S. Bohacek, G. P. Luke, M. Hatada, X. D. Lu, D. C. Dalgarno, S. S. Narula, R. Yuan and D. A. Holt, Bioorg. Med. Chem. Lett., 1999, 9, 2353.

13 J. M. Fu and A. L. Castelhano, Bioorg. Med. Chem. Lett., 1998, 8, 2813.

14 G. Waksman, S. E. Shoelson, N. Pant, D. Cowburn and J. Kuriyan, Cell, 1993, 72, 779.

15 M. R. Groves, Z. J. Yao, P. P. Roller, T. R. Burke and D. Barford, Biochemistry, 1998, 37, 17773.

16 H. Fretz, Tetrahedron, 1998, 54, 4849.

17 T. R. Burke, J. Luo, Z. J. Yao, Y. Gao, H. Zhao, G. W. A. Milne, R. B. Guo, J. H. Voigt, C. R. King and D. J. Yang, Bioorg. Med. Chem. Lett., 1999, 9, 347.

18 S. D. Taylor, C. C. Kotoris, A. N. Dinaut and M. J. Chen, Tetrahedron, 1998, 54, 1691.

19 S. D. Taylor, C. C. Kotoris, A. N. Dinaut, Q. P. Wang, C. Ramachandran and Z. Huang, Bioorg. Med. Chem., 1998, 6, 1457.

20 S. D. Taylor, A. N. Dinaut, A. N. Thadani and Z. Huang, Tetrahedron Lett., 1996, 37, 8089.

21 K. Sato, R. Kawata, F. Ama, M. Omote, A. Ando and I. Kumadaki, Chem. Pharm. Bull., 1999, 47, 1013.

22 T. R. Burke, B. Ye, M. Akamatsu, H. Ford, X. J. Yan, H. K. Kole, G. Wolf, S. E. Shoelson and P. P. Roller, J. Med. Chem., 1996, 39, 1021.

23 P. P. Roller, L. Wu, Z. Y. Zhang and T. R. Burke, Bioorg. Med. Chem. Lett., 1998, 8, 2149.

24 Z. G. Li, S. L. Yeo, C. J. Pallen and A. Ganesan, Bioorg. Med. Chem. Lett., 1998, 8, 2443.

25 G. Bergnes, C. L. Gilliam, M. D. Boisclair, J. L. Blanchard, K. V. Blake, D. M. Epstein and K. Pal, Bioorg. Med. Chem. Lett., 1999, 9, 2849.

26 G. S. Cockerill, H. J. Easterfield and J. M. Percy, Tetrahedron Lett., 1999, 40, 2601.

27 T. Yokomatsu, T. Murano, I. Umesue, S. Soeda, H. Shimeno and S. Shibuya, Bioorg. Med. Chem. Lett., 1999, 9, 529.

28 T. Yokomatsu, T. Murano, K. Suemune and S. Shibuya, Tetrahedron, 1997, 53, 815.

29 A. Echavarren and J. K. Stille, J. Am. Chem. Soc., 1987, 109, 5478.

30 M. Rottlander and P. Knochel, J. Org. Chem., 1998, 63, 203.

31 Electron-poor aryl halides undergo oxidative addition to $\operatorname{Pd}(0)$ complexes more readily than electron-rich counterparts; see A. F. Litke and G. C. Fu, J. Org. Chem., 1999, 64, 10 and V. V. Grushin and H. Alper, Chem. Rev., 1994, 94, 1047 for a recent example and review respectively.

32 E. M. Kampouris, J. Chem. Soc., 1965, 2651; J. E. Baldwin, D. H. R. Barton, I. Dainis and J. L. C. Pereira, J. Chem. Soc. C, 1968, 2283.

33 V. Farina, S. Kapadia, B. Krishnan, C. Wang and L. S. Liebeskind, J. Org. Chem., 1994, 59, 5905.

34 Q.-Y. Chen and Z.-Y. Yang, Tetrahedron Lett., 1986, 27, 1171.

35 W.-C. Shieh and J. A. Carlson, J. Org. Chem., 1992, 57, 379.

36 N. A. Caplan, C. I. Pogson, D. J. Hayes and G. M. Blackburn, J. Chem. Soc., Perkin Trans. 1, 2000, 421 .

37 Vogel's Textbook of Practical Organic Chemistry, Longman Scientific and Technical, New York, 1989, 5th edn., p. 428. 